\title{
تطبيقات الاستقراء في المسائل العقدية عند الرازي من خلال التفسير الكبيز
}

\author{
د. نعمان نافع عبيد الكبيسي \\ قسم علوم القرآن ـ الجامعة العراقيّة العبية

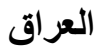

الملخص

يسعى هذا البحث إلى الوقوف على مفهوم الاستقر اء، من خلال دراسة تدبرية وتحليلية لمو اطن الاستقر اء في

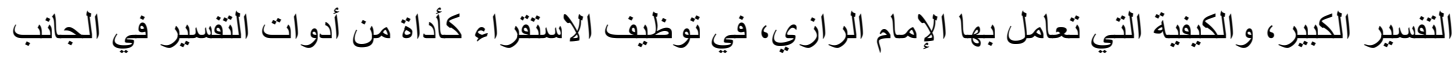
العقدي.

كما حرص البحث على إظهار معالم الاستقراء في المسائل العقدية، التي قام بها الرازي، فجاء البحث مكونا من مقدمة ومبحثين وخاتمة.

وقد توصل البحث إلى عدة نتائج من أبرزها، فاعلية الاستقر اء كوسيلة في تحرير المعنى القرآني في المسائل

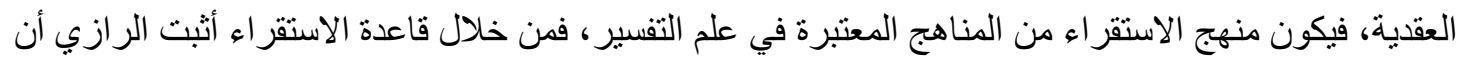
هداية الخلق واقعة ضمن مشيئة الله تعالى وتقديره، وكذلك اعتمد قاعدة الاستقر اء في إدحاض شبهة المشبهة بأن الله تعالى نور، وأيضا من خلال الاستقر اء استدل الرازي بأنه لا يمكن إدر الك حقيقة الله تعالى من خلال مدارك الك اله

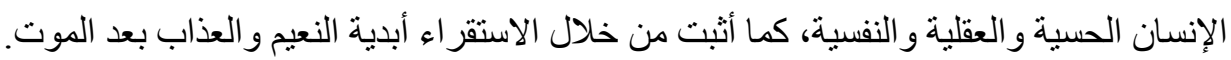

الكلمات المفتاحية: الاستقر اء، العقيدة، الرازي. 


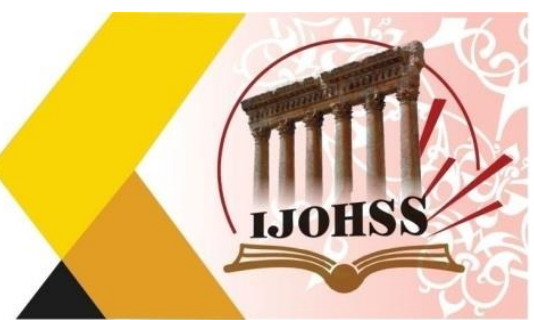

\title{
Applications of Induction in Doctrinal Issues According to Al-Razi Through The Great Interpretation
}

\author{
Dr. Numan Nafeh Obaid Al Kubaisi \\ Department of Quranic Sciences \\ Iraqi University \\ Iraq
}

\begin{abstract}
This research seeks to identify the concept of induction, through a deliberative and analytical study of the areas of induction in the great interpretation, and how Imam Al-Razi dealt with the employment of induction as a tool of interpretation in the doctrinal aspect.

The research was also keen to show the features of induction in the doctrinal issues, which was carried out by Al-Razi, so the research was composed of an introduction, two chapters and a conclusion.

The research reached several results, most notably, the effectiveness of induction as a means in editing the Qur'anic meaning in doctrinal issues, so the induction approach is one of the considered approaches in the science of interpretation. In refuting the suspicion of the suspect that God Almighty is light, and also through induction, alRazi inferred that it is not possible to comprehend the truth of God Almighty through man's sensory, mental and psychological perceptions, as he proved through induction the eternity of bliss and torment after death.
\end{abstract}

Keywords: induction, doctrine, Al-Razi. 


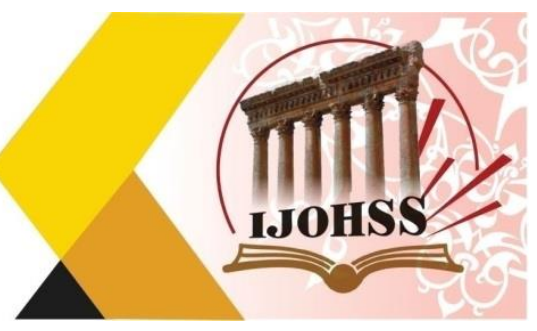

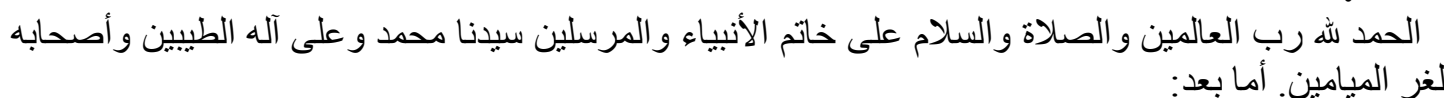

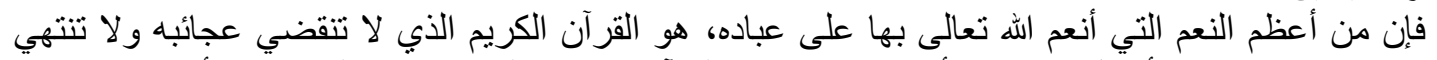

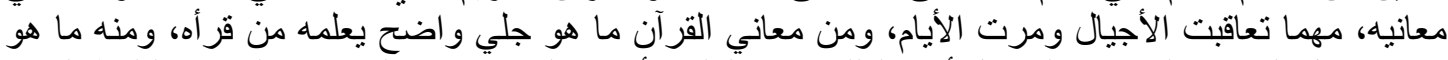

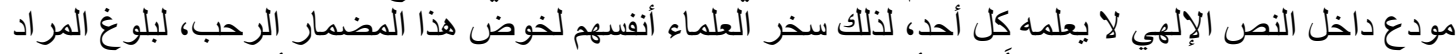

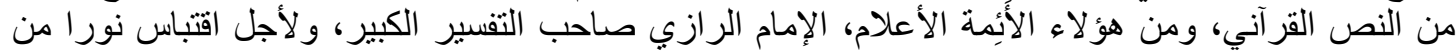

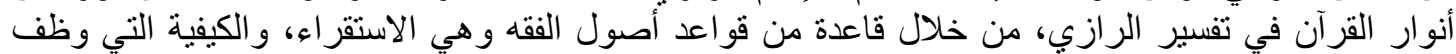

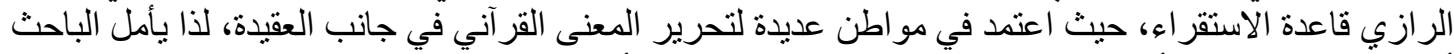

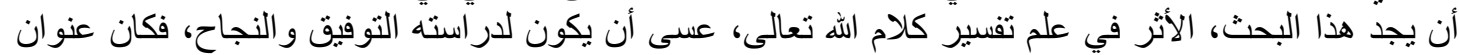

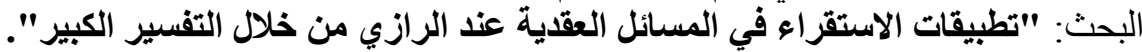

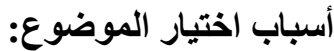
1ـ الارتباط الوثيق بين علم تفسير كتاب الله تعالى و علم أصول الدين.

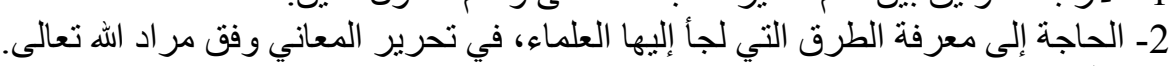

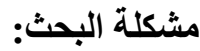

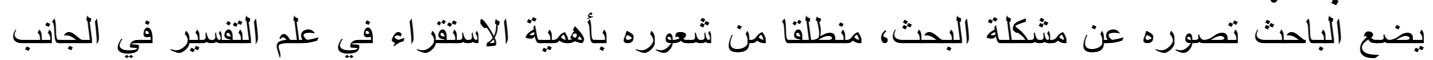

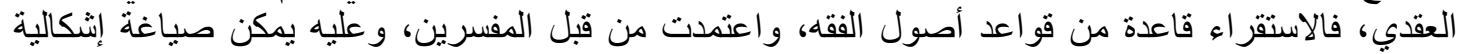

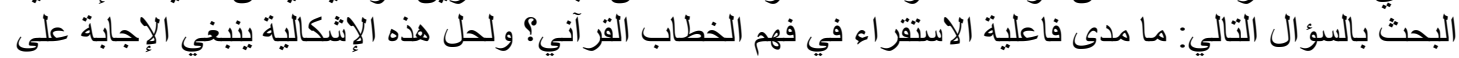

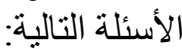

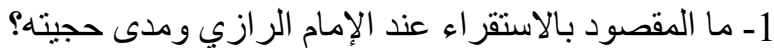
2- هل اعتمد الرازي قاعدة الاستقر اء في التفسير الكبير لتحرير المعنى في المسائل العقدية؟

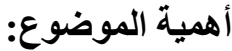

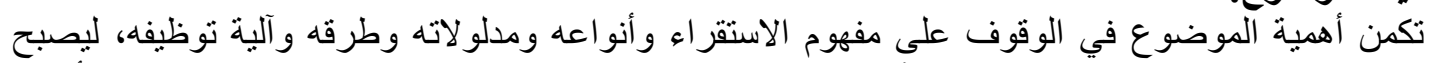

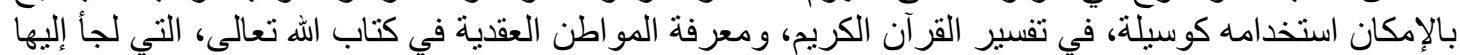

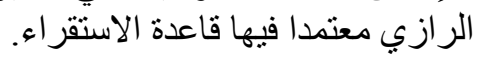

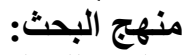

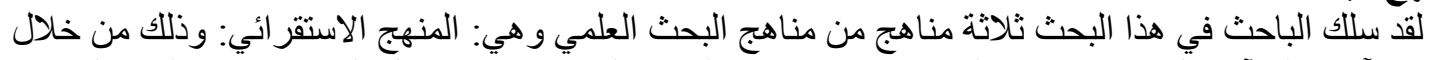

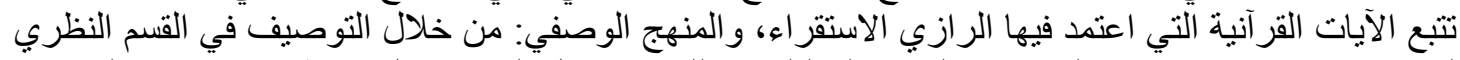

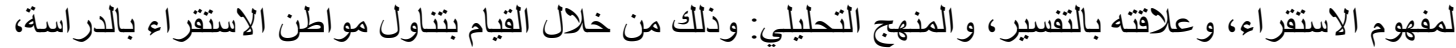

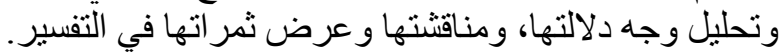

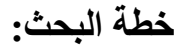

تكون البحث من مقدمة ومبحثين وخاتمة، فجاء المبحث الأول بعنوان: تمهيد في مقدمات الاستقراء ونبذة الأنة

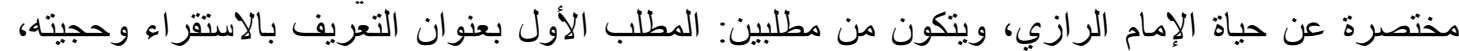

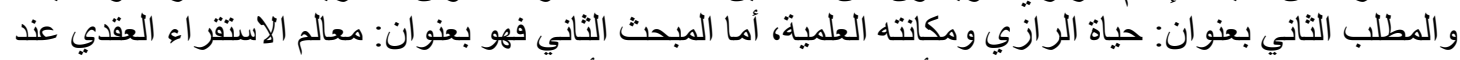

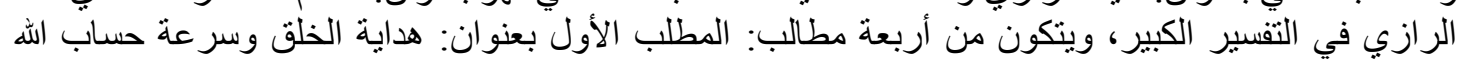

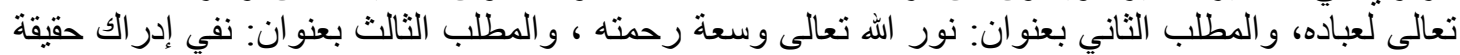

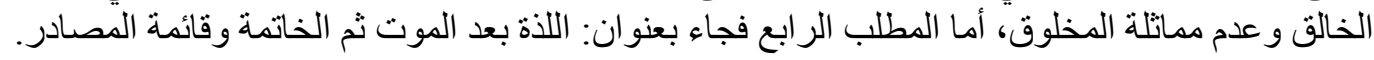

المبحث الأول: تمهيد في مقدمات الاستثراء ونبذة مختصرة عن حياة الإمام الرازي

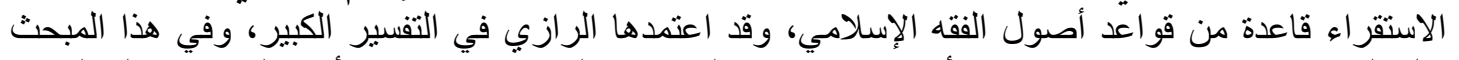

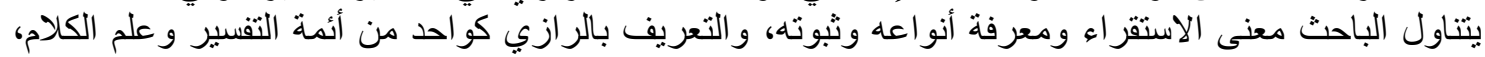

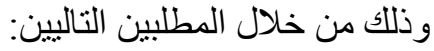


العدد (25) أكتوبر 2021

ISSN: $2415-4822$

Volume (25) October 2021

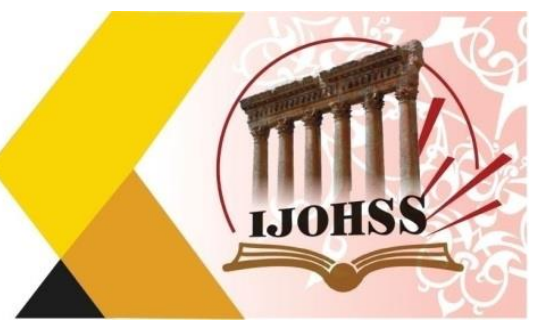

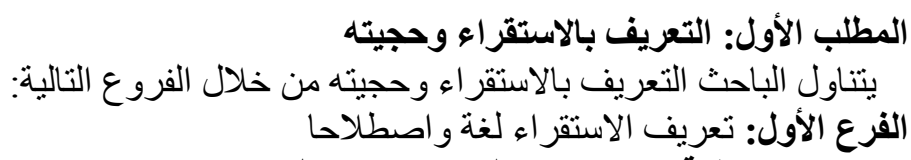

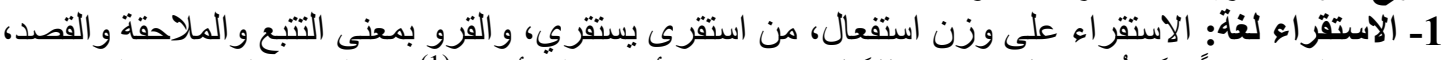

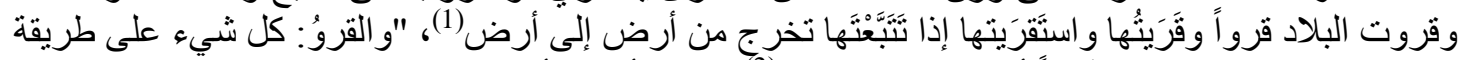

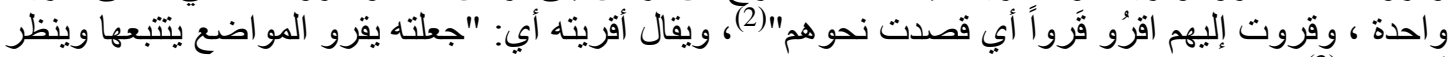

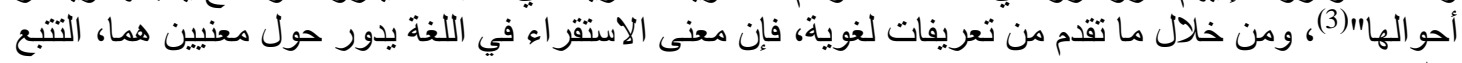

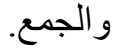

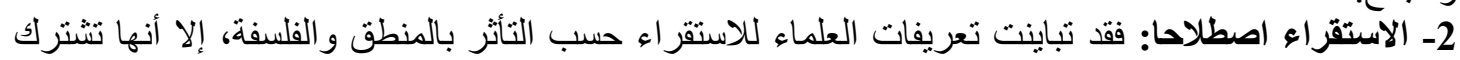

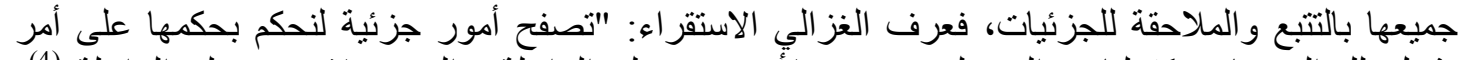

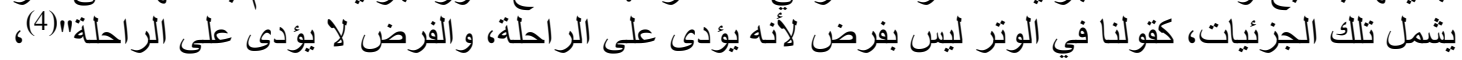

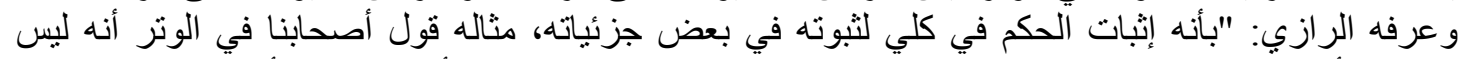

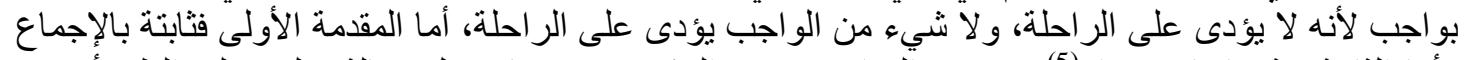

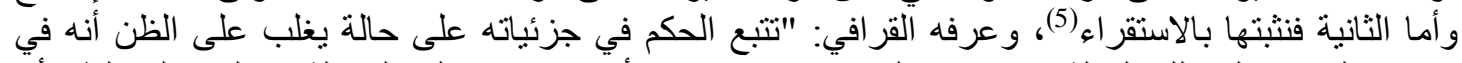

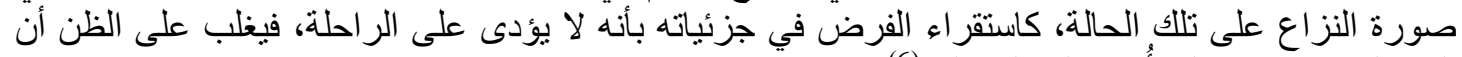

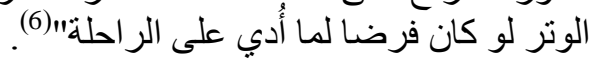

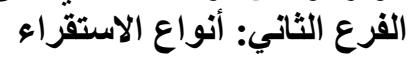

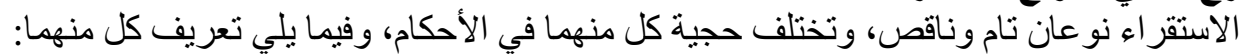

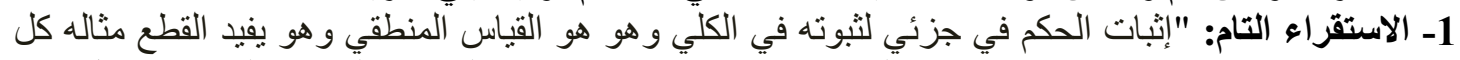

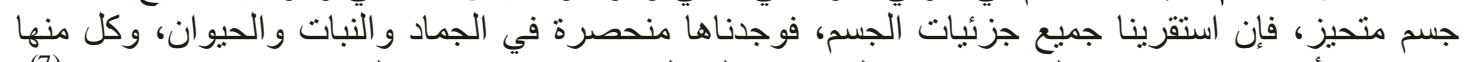

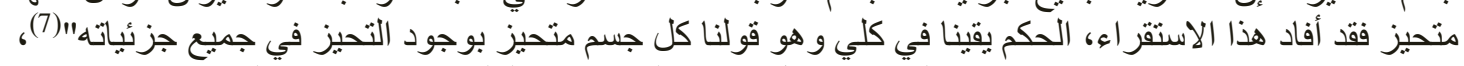

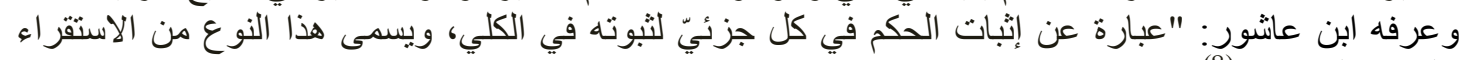
بالقياس المنطقي"(8) - (8).

(1) ينظر : ابن منظور: محمد بن مكرم(المتوفي: 711ه)، لسان العرب، دار صادر، بيروت، الطبعة: الثالثة، 1414ه،

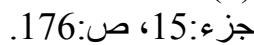
(2) الفر اهيدي: أبو عبداله الخليل بن أحمد البصري(المنوفى:170ه)، العين، تحقيق: مهدي المخزومي و إبراهيم السامر ائي،

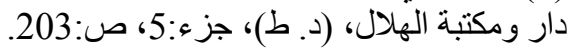

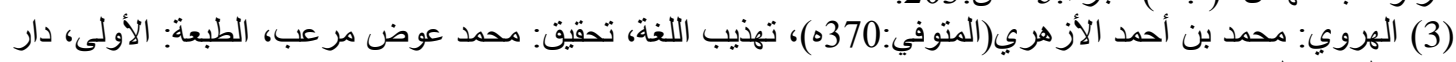

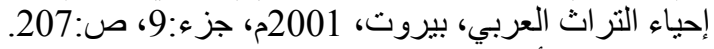

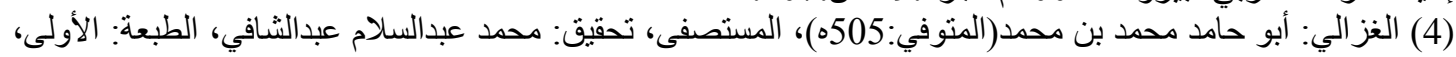

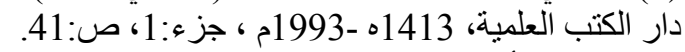

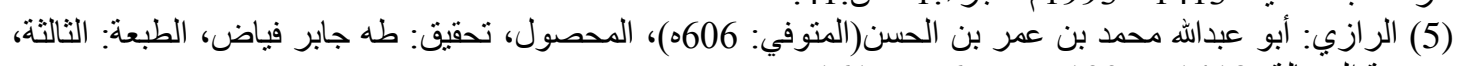

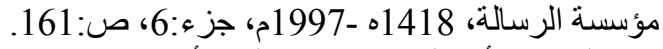

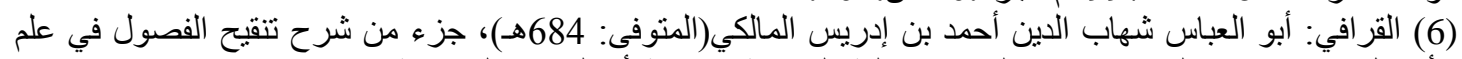

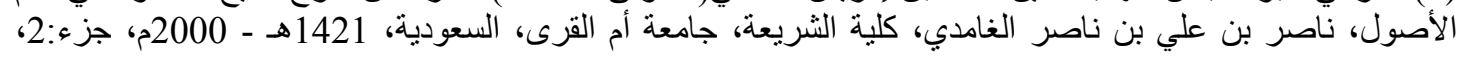

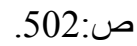
(7) ابن السبكي: نقي الدين أبو الحسن علي بن عبد الكافي(المنوفى: 756هـ)، الإبهاج في شرح المنهاج، دار الكتب

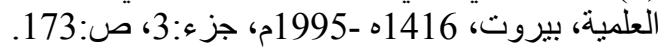

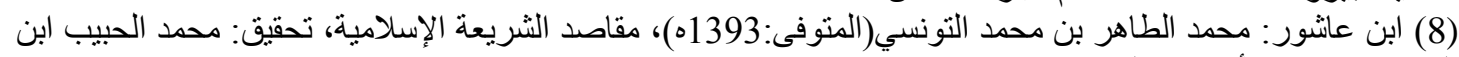
الخوجة، وزارة الأوقاف و الثؤون الإسلامية، قطر، 1425 هـ - 2004م، جزء ع:2، ص:243. 


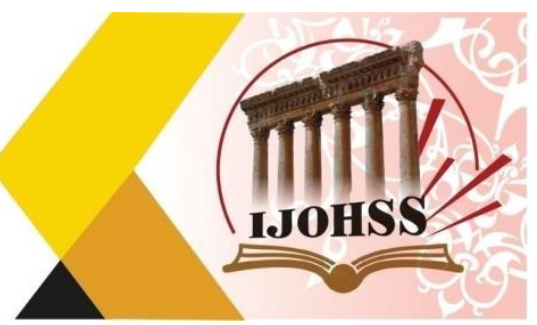

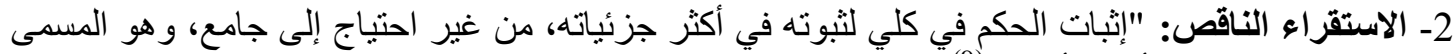

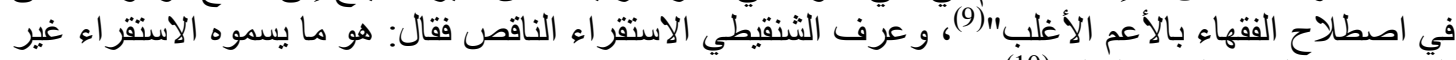
التام ومعناه إلحاق الفرد بالغاءلب(10).

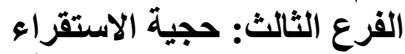

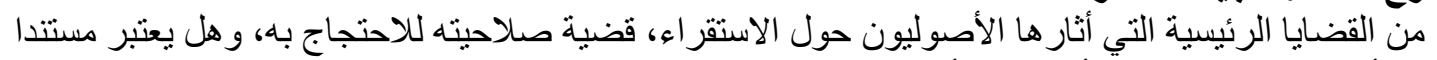

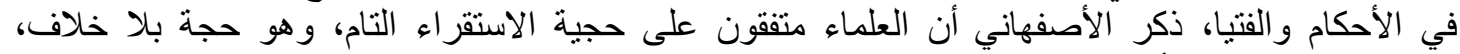

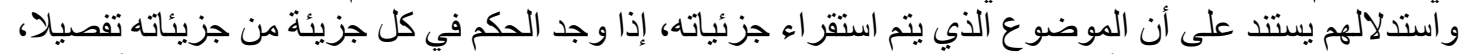

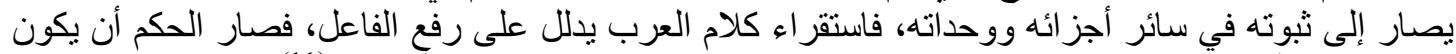

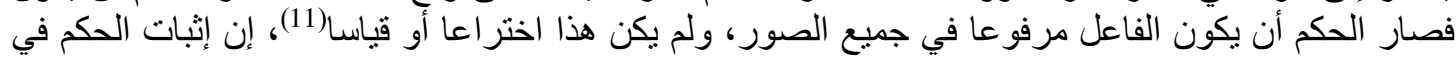

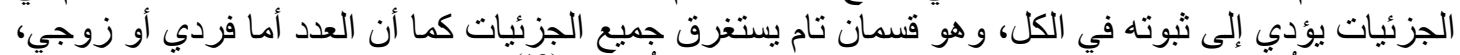

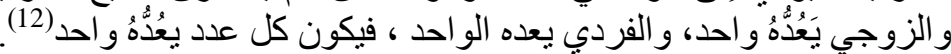

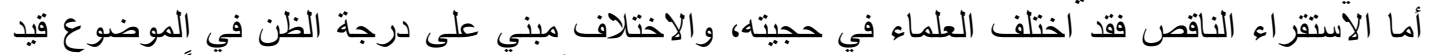

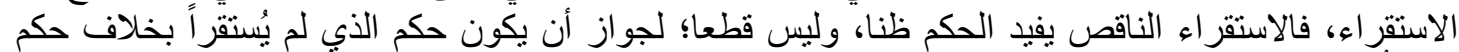

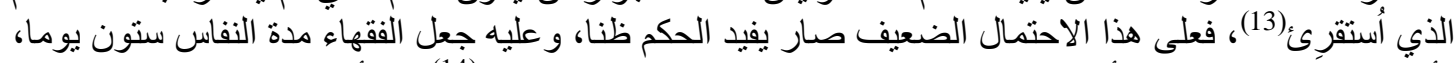

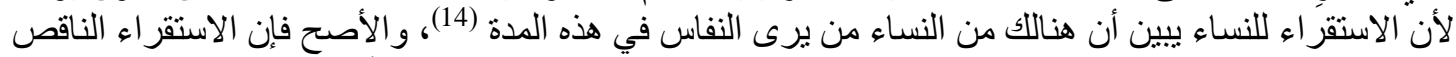

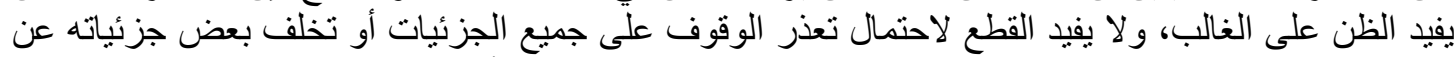

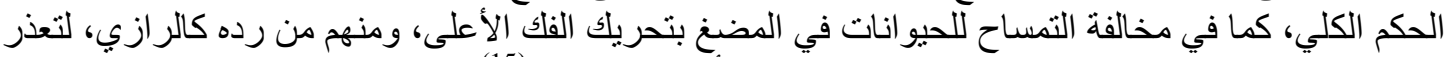

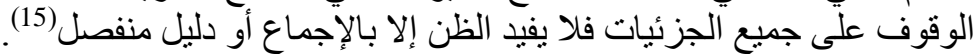

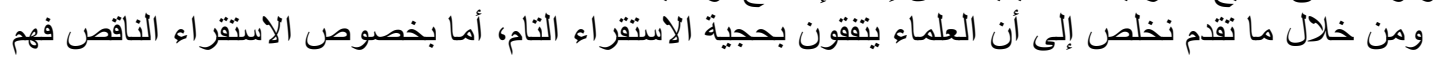

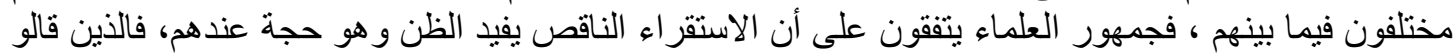

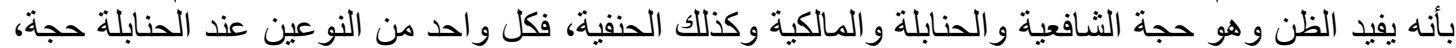

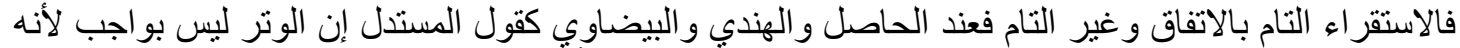

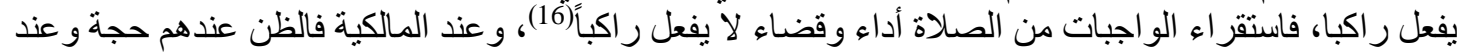

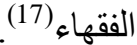

(9) ينظر : الزركشي: أبو عبد الله بدر الدين محمد بن عبد الله(المتوفى: 794هـ)، البحر المحيط في أصول الفقه، الطبعة:

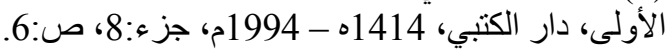

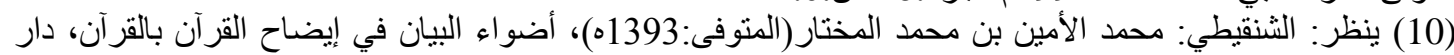

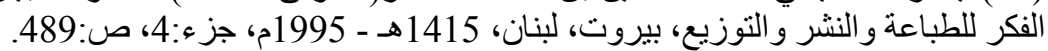

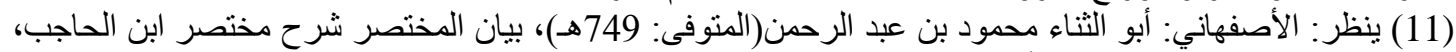

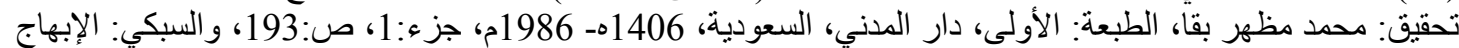

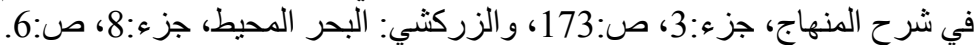

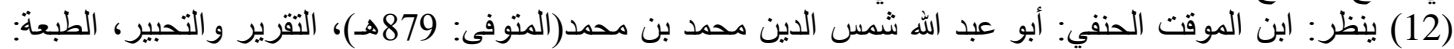

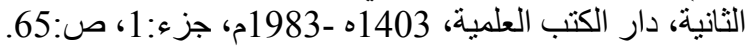
(13) ينظر: النملة: عبد الكريم بن علئ علي بن محمد النملة، الجامع لمسائل أصول الفقه وتطبيقاتها على المذهب الراجح،

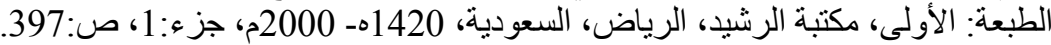

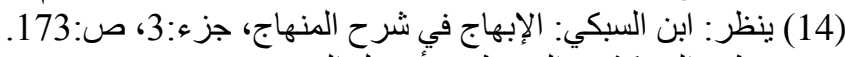

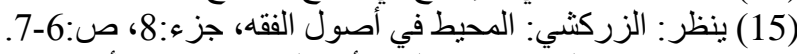

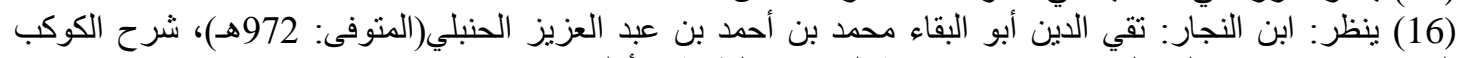

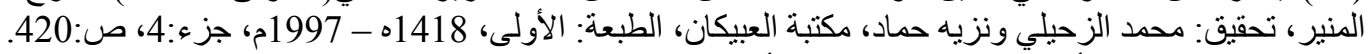

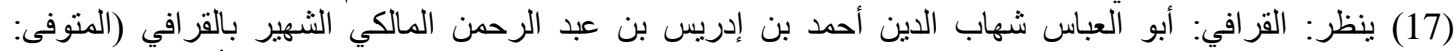

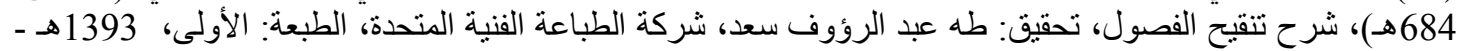

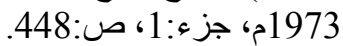




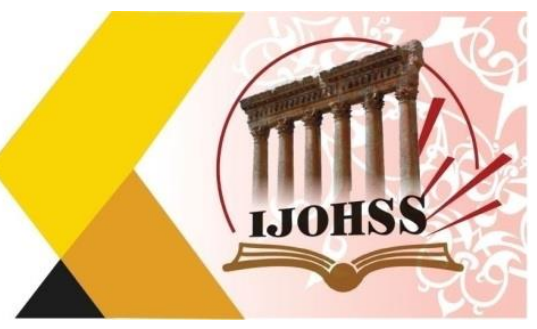

المطلب الثاني: حياة الرازي ومكانته العلمية

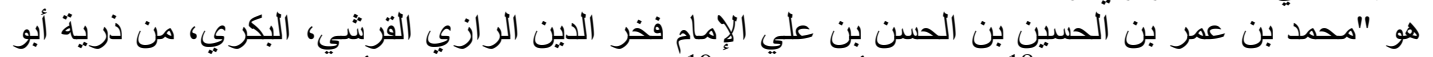

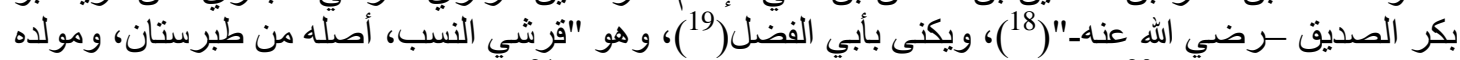

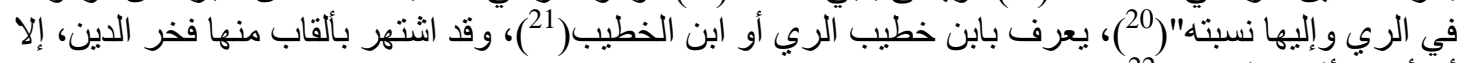

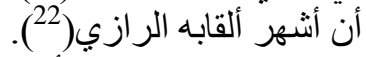

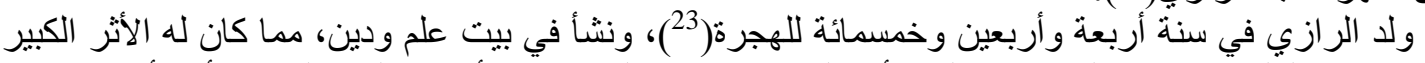

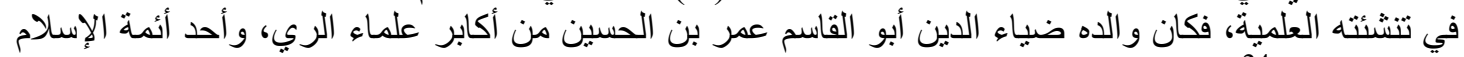

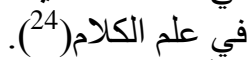

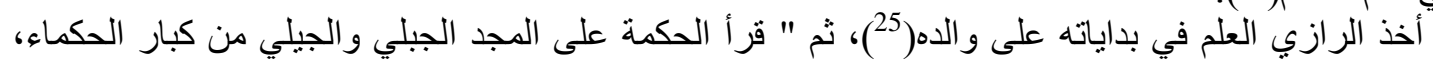

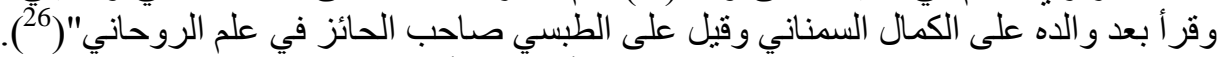

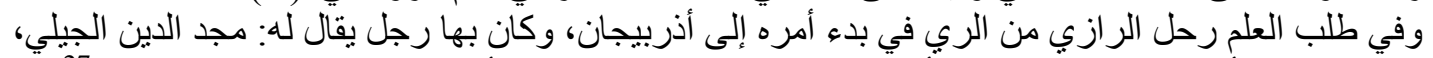

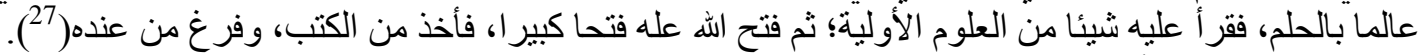

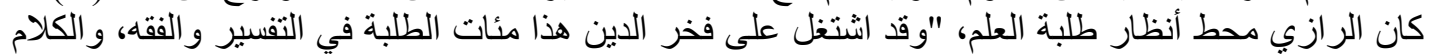

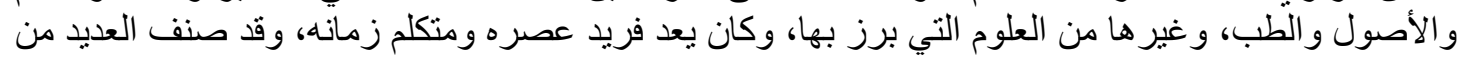

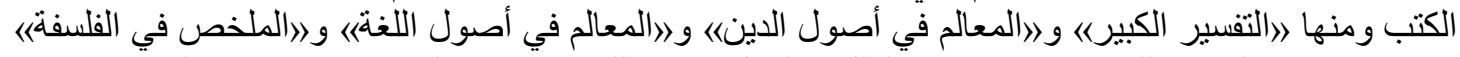

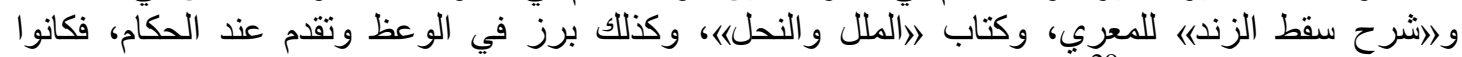

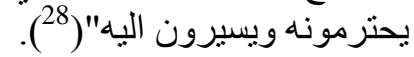

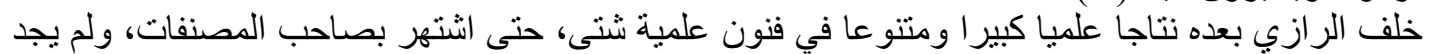

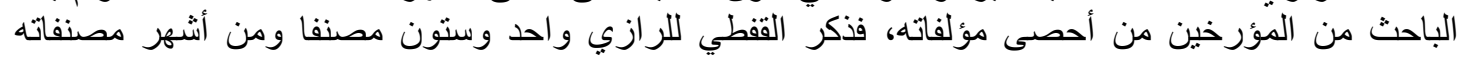

(18) السيوطي: عبد الرحمن بن أبي بكر، جلال الدين(المتوفى: 911هـ)، طبقات الدفسرين العثرين، تحقيق: علي محمد

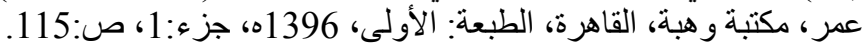

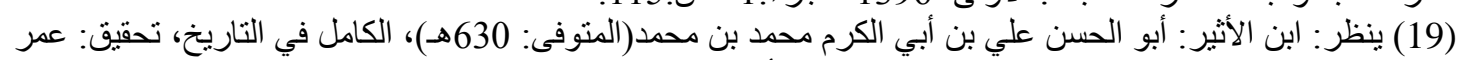

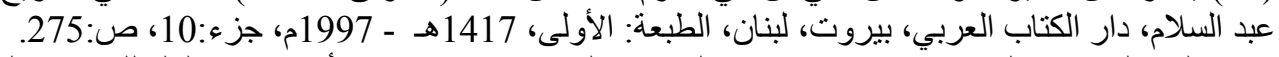

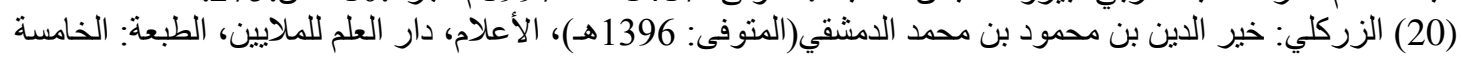

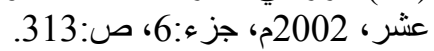

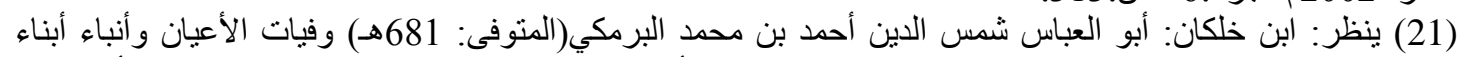

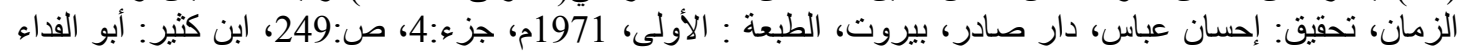

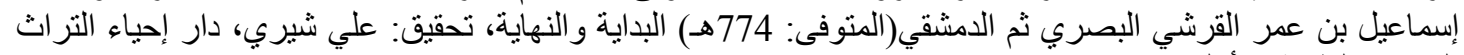

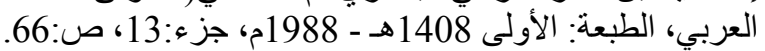

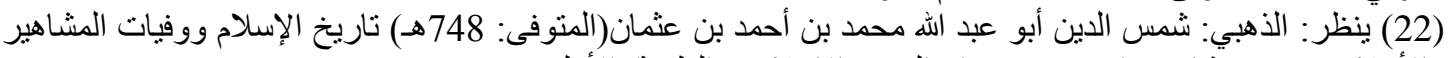

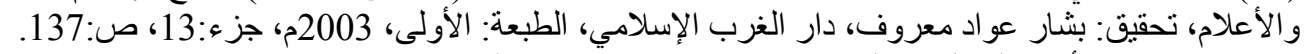

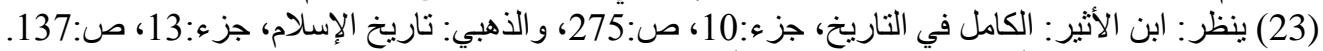

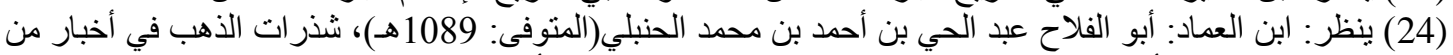

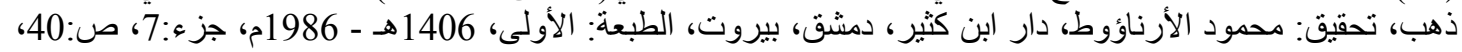

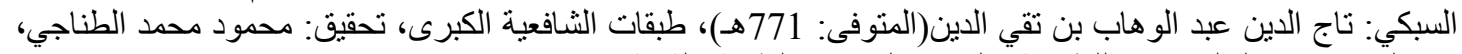

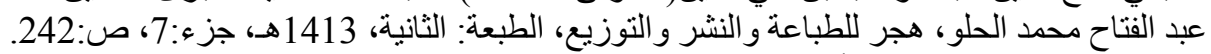

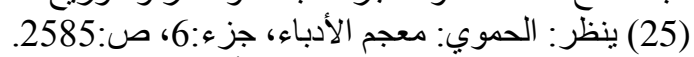

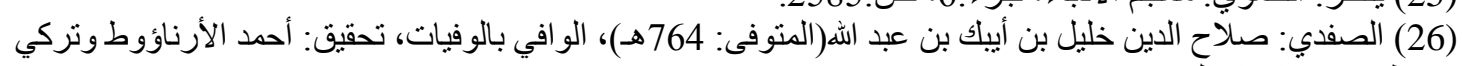

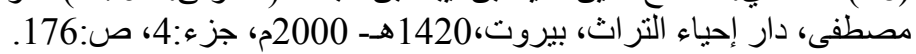

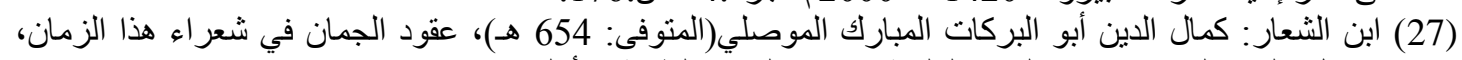

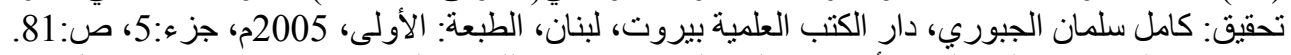

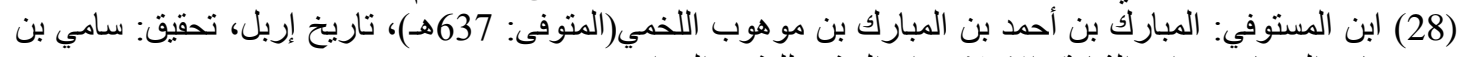

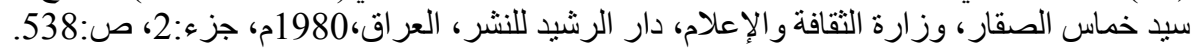




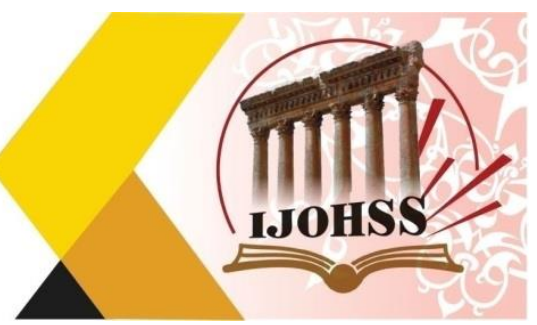

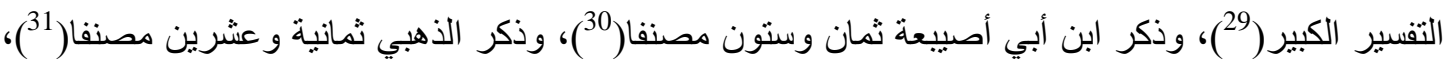

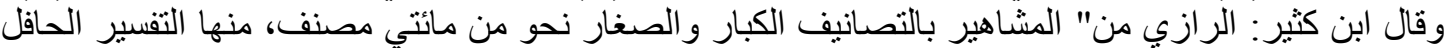

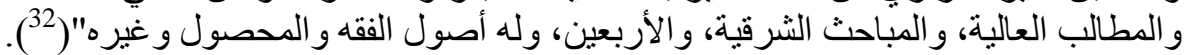

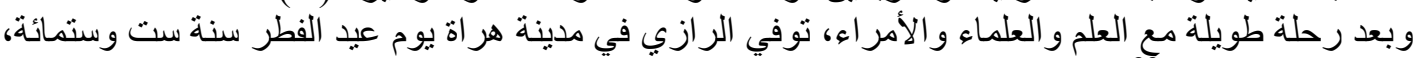

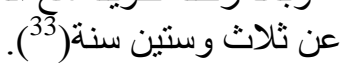

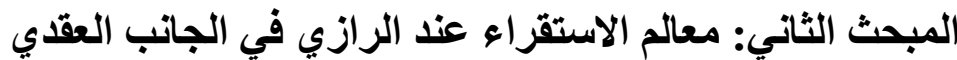

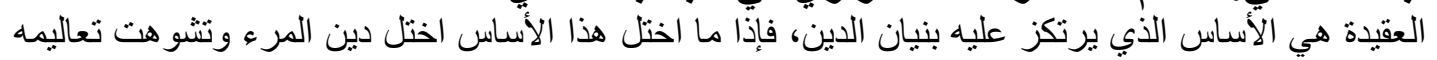

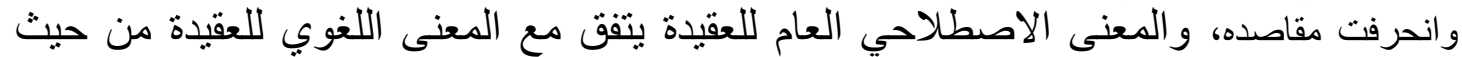

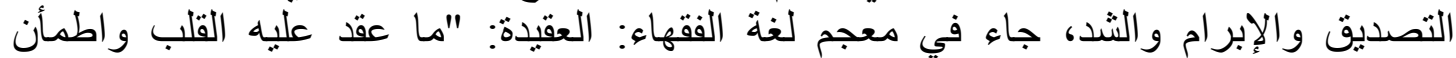
إليه"(34)، في هذا المطلب يتناول الباحث نطبيقات الاستقراء عند الر ازي في جانب العبدة العقيدة.

المطلب الأول: هداية الخلق وسرعة حساب الله تعالى لعباده

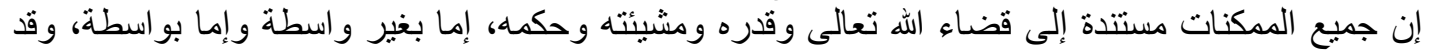

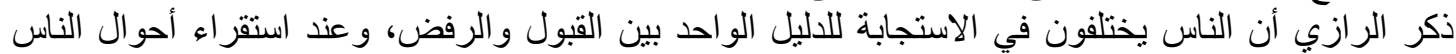

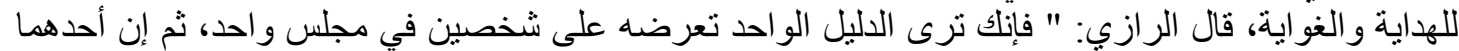

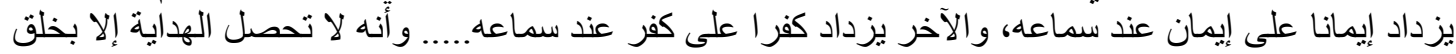

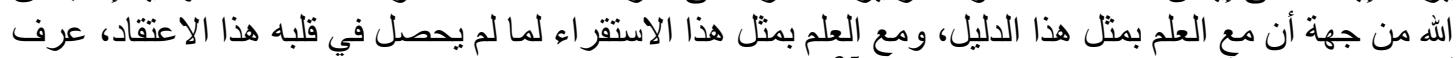

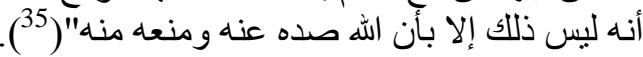

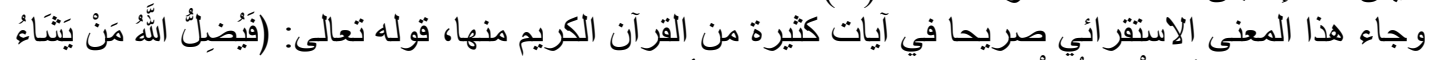

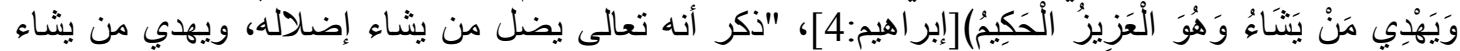

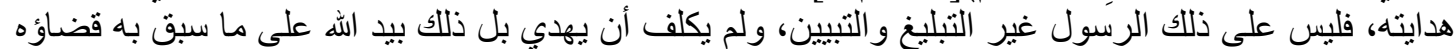

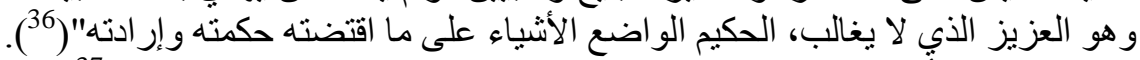

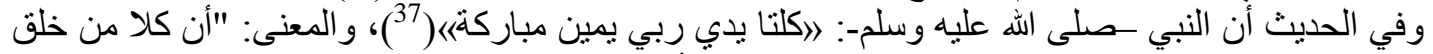

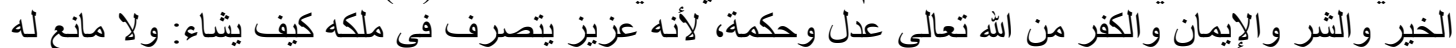

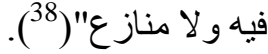

(29) ينظر: القفطي: جمال الدين أبو الحسن علي بن يوسف بن إبر اهيم الثيباني(المتوفى: 646هـ)، إخبار العلماء بأخبار

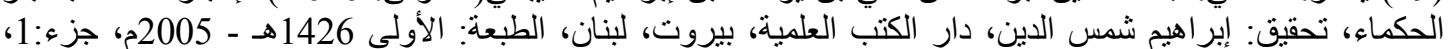
ص:221-220 (220) (30) ينظر : ابن أبي أصيبعة: عيون الأنباء في طبقات الأطباء، جزء:13، ص:137 ص:470-471-4.

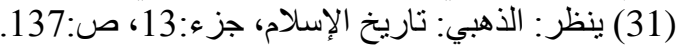

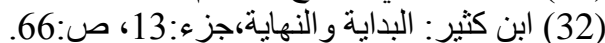

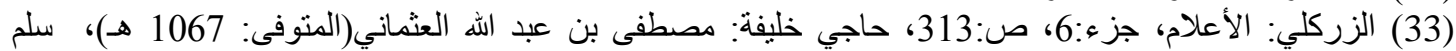
الوصول إلى طبقات الفحول، تحقيق: محمود عبد القادر الأرناؤوط، مكتبة إرسيكا، إستانبول، تركيا، 2010م، جزء:3، هـ،

(34)معجم لغة الفقهاء: محمد رواس قلعجي، وحامد صادق قنيبي، دار النفائس للطباعة والنشر و التوزيع، ط2، 1408هـ ـ

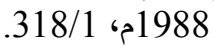

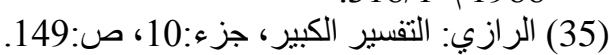

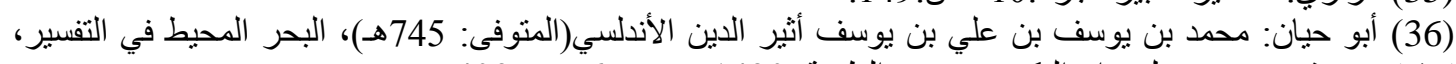

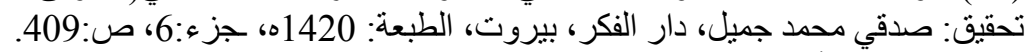

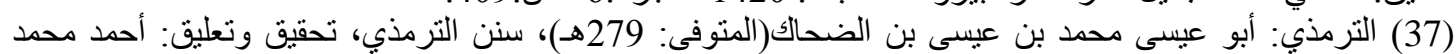

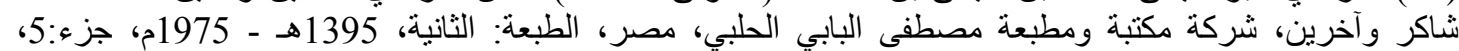
ص:453، أبواب تفسير القرآن عن رسول الله -صلى أله عليه وسلم-، حديث برقم:3368، ابن حبان: محمد بن أحمد بن 


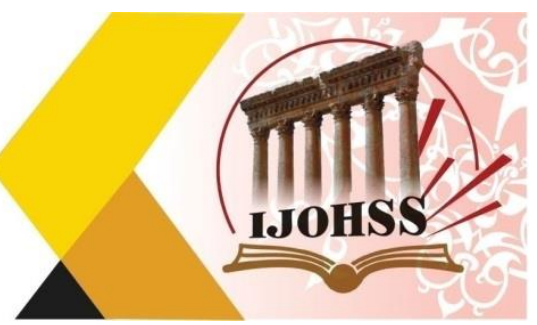

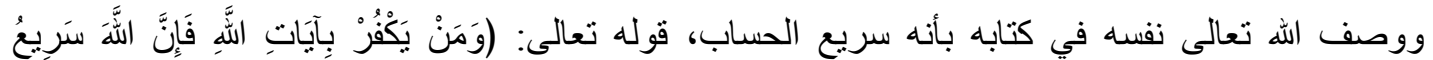

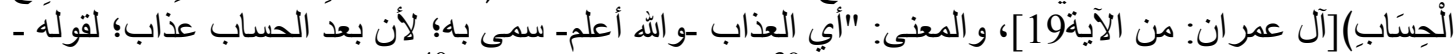

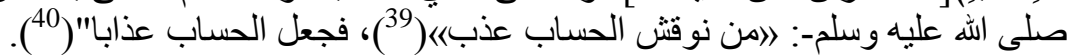

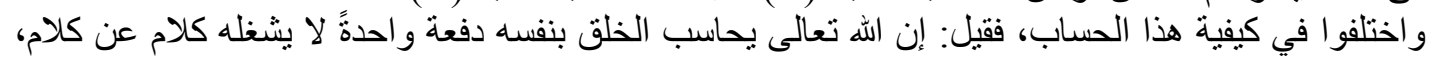

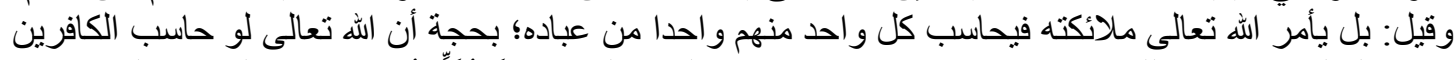

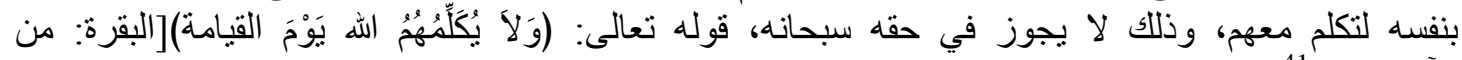
الآية174) وقد رجح الرازي أن لا فعل من أفعال الخير والثر بقليل و لا كثير إلا وله أثر في النفس، إما في السعادة، وإما

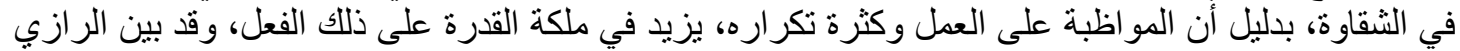

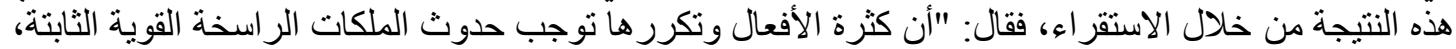

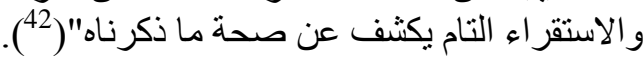

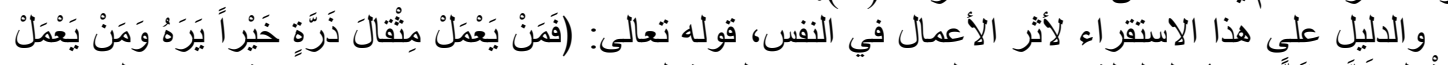

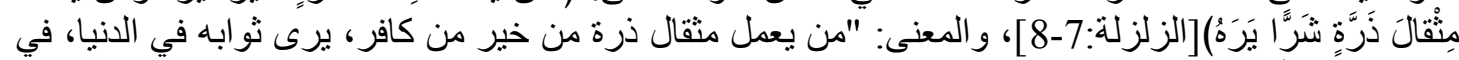

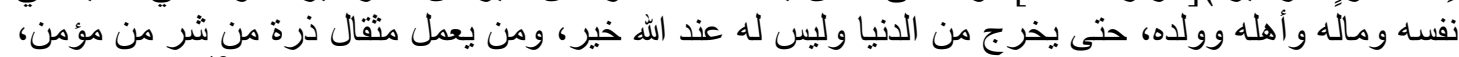

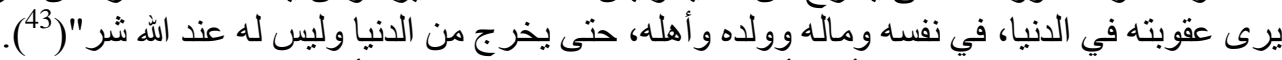

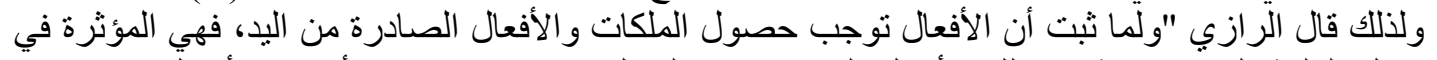

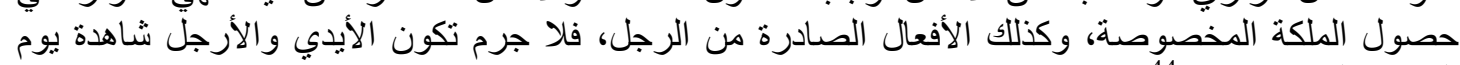
القيامة على الإنسان"(44). (44).

المطلب الثاني: نور الله تعالى وسعة رحمته

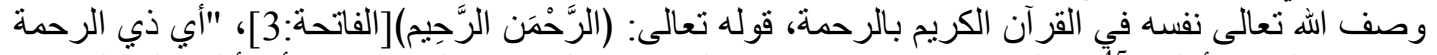

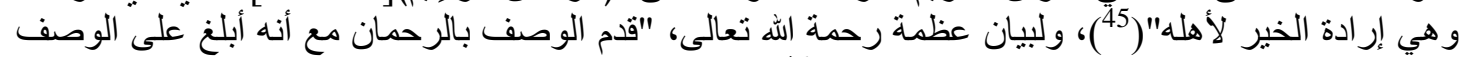

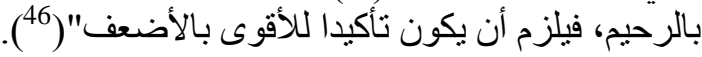

حبان بن معاذ، التميمي البستي(المتوفى: 354هـ)، صحيح ابن حبان بترتيب ابن بلبان، تحقيق: شعيب الأرنؤوط، مؤسسة

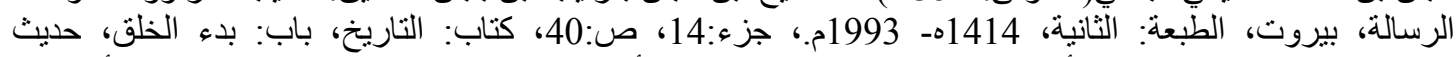

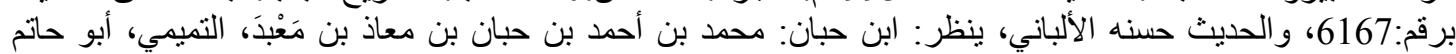

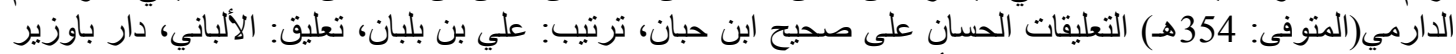

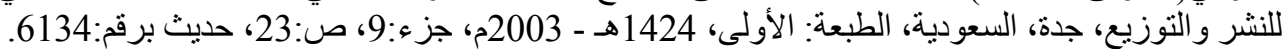

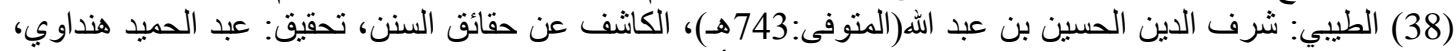

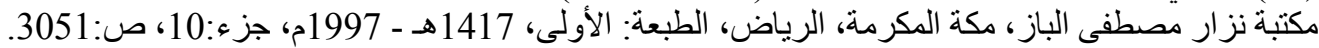

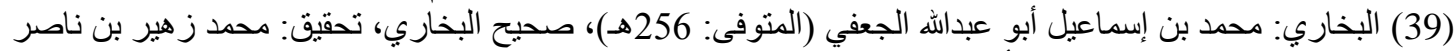

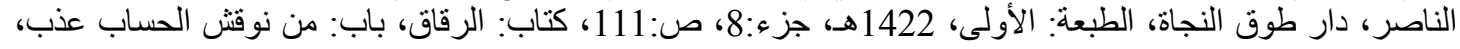
حديث برقم:6536.

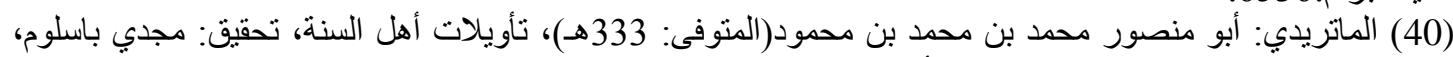

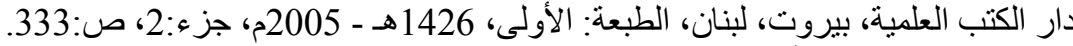

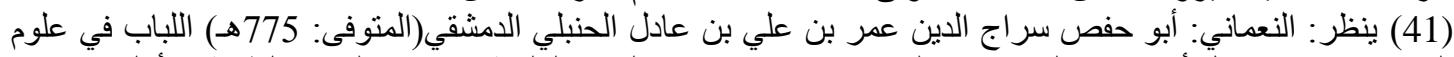

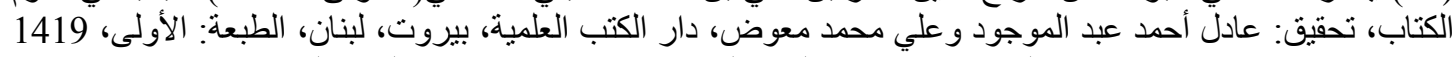

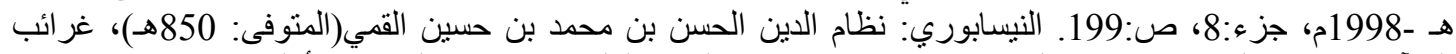

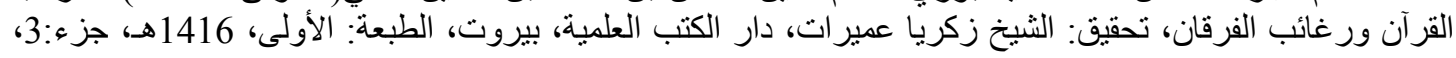




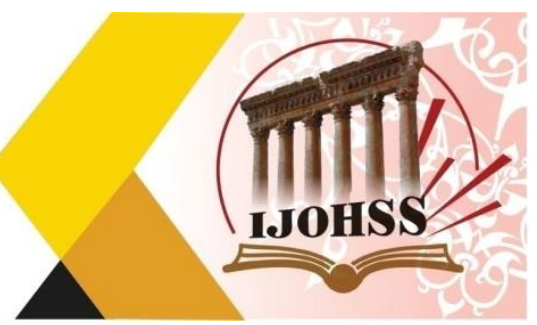

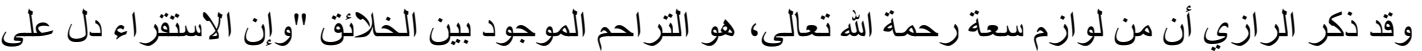

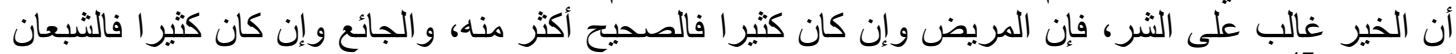

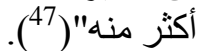

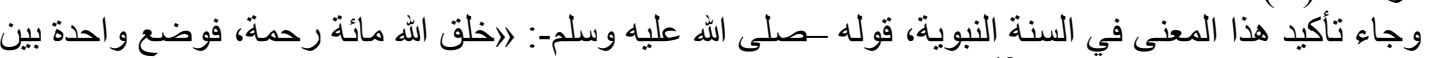

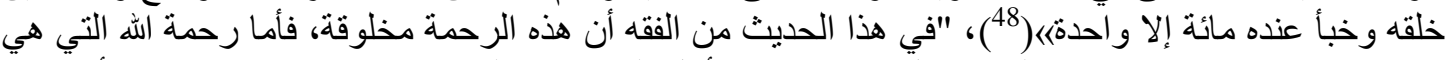

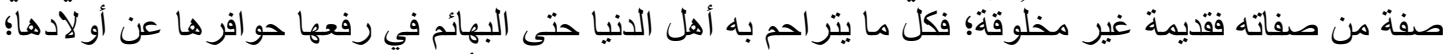

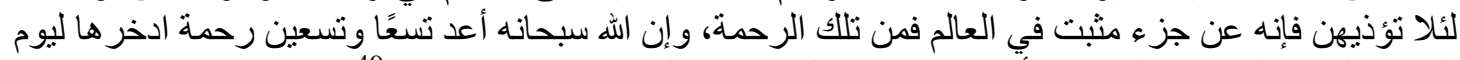

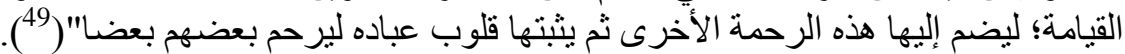

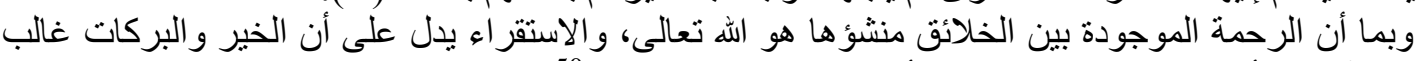

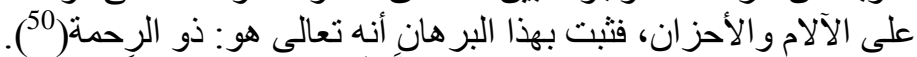

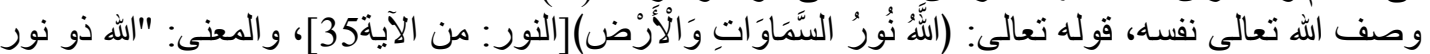

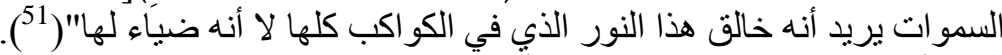

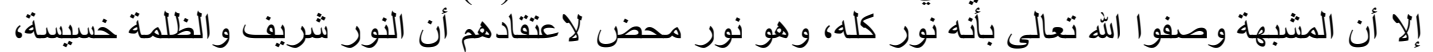

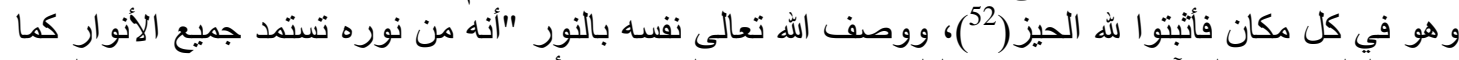

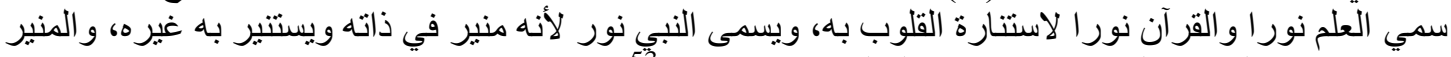

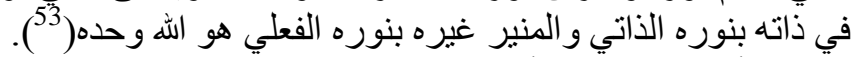

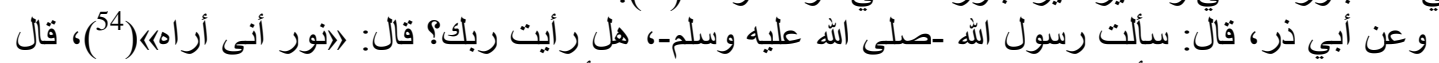

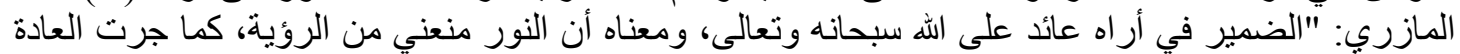

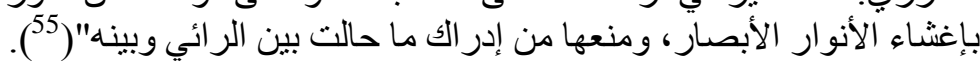

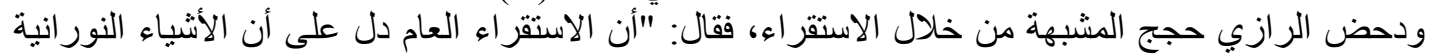

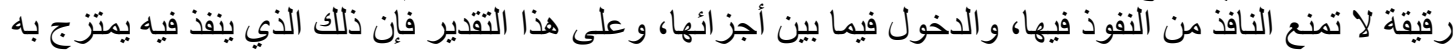

(45) جلال الدين: محمد بن أحمد الدحلي(المنوفى: 864هـ)، وجلالال الدين عبد الرحمن بن أبي بكر السيوطي (المنوفى:

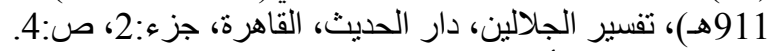

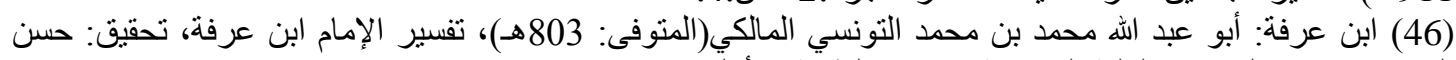

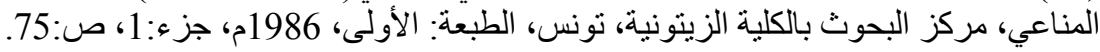

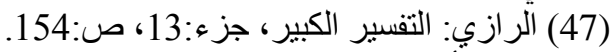

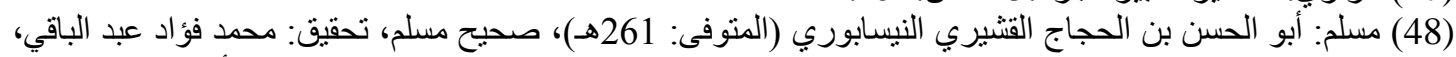
دار إحياء التراث العربي، بيروت، جزء:4، ص:2108، كتاب: التوبة، باب: في سعة رحمة الله تعالى و أنها سبقت غضبنه، حديث برقم:2752. (49) ابن هبيرة: أبو المظفر ، عون الدين يحيى بن محمد الذهلي الثشيباني(المتوفى: 560هـ)، الإفصاح عن معاني الصحاح،

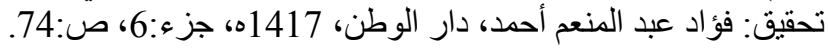

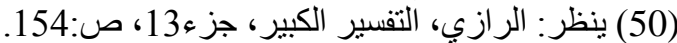

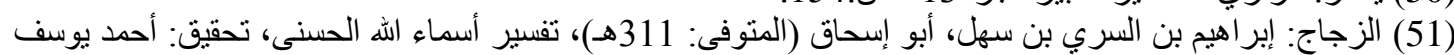

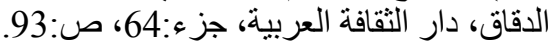

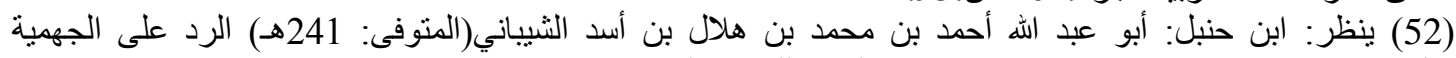

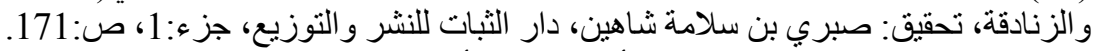

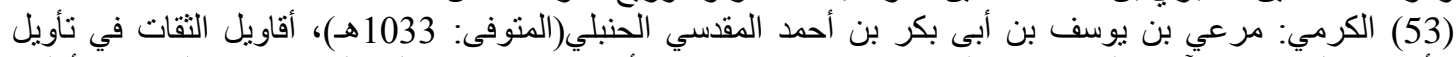

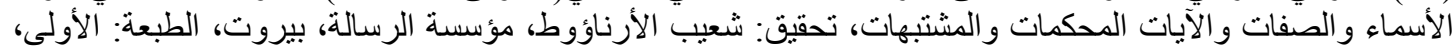

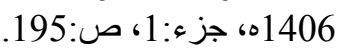

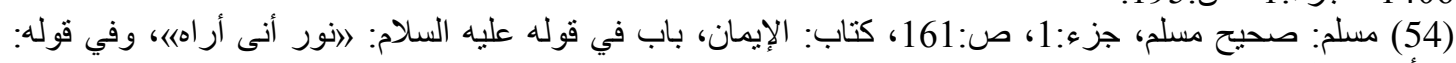

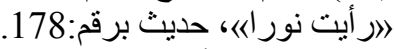

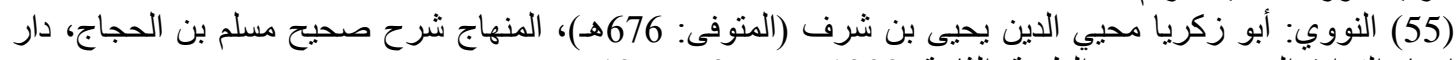

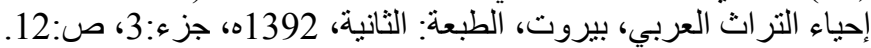


ويفرق بين أجزائه، ويكون ذلك الثيء جاريا مجرى الهواء الذي يتصل تارة وينفصل أخرى، ويجتمع تارة

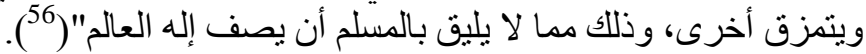

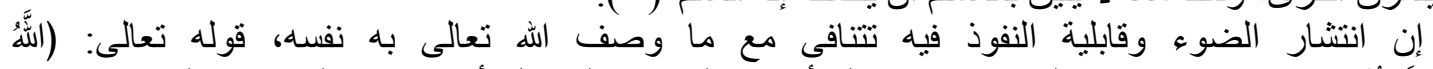

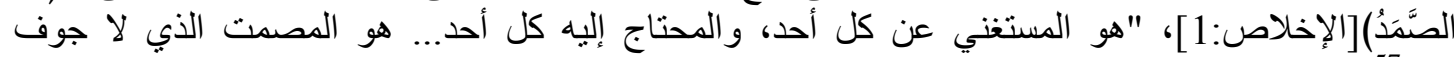
. له

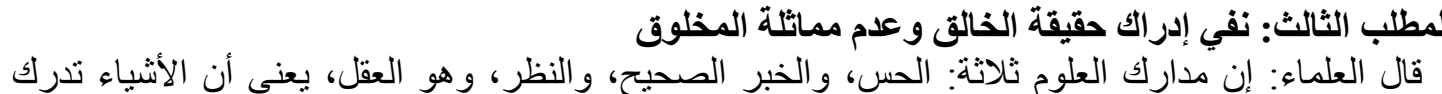

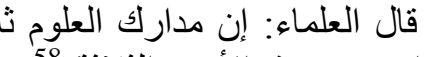

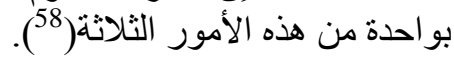

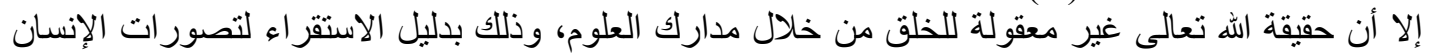

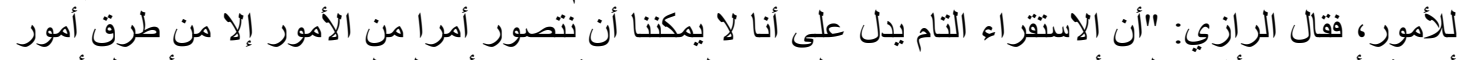

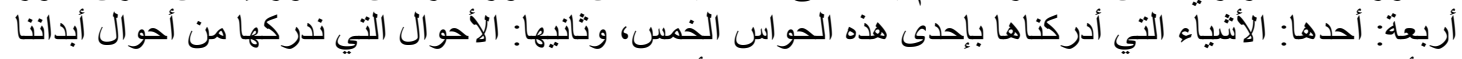

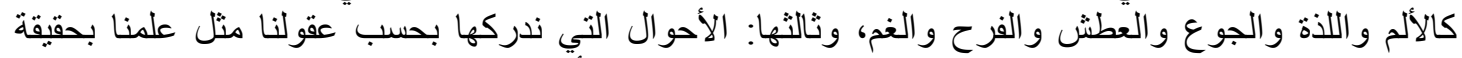

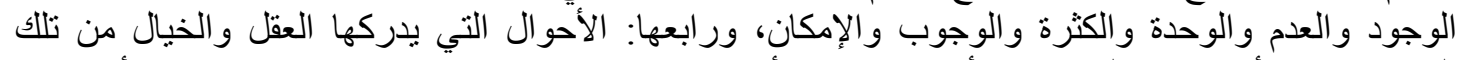

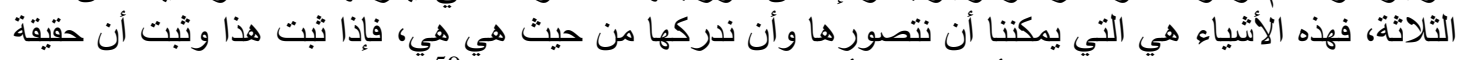

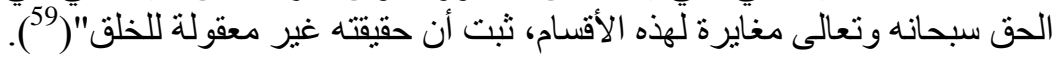

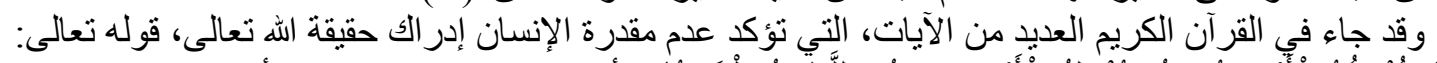

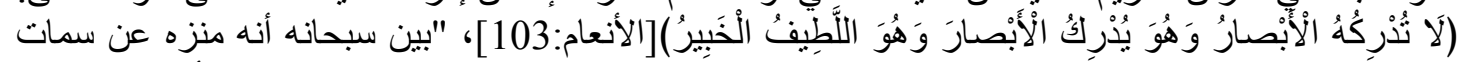

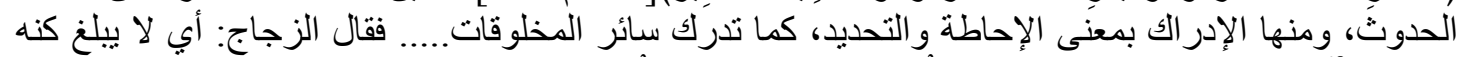

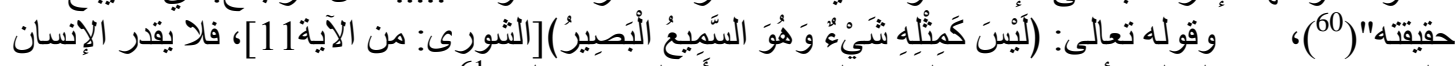

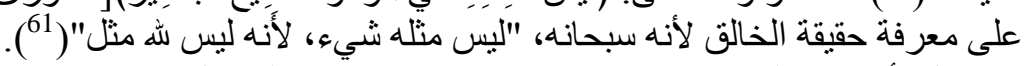

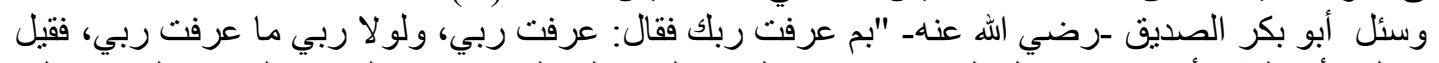

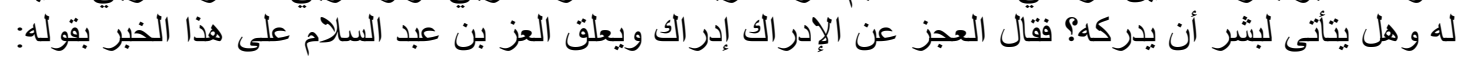

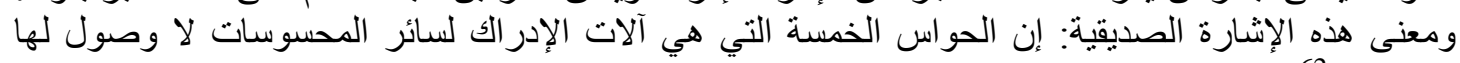

لإدر اكه"( (20).

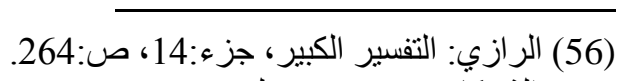

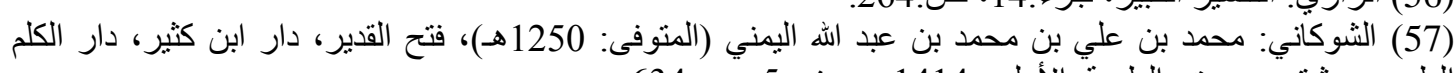

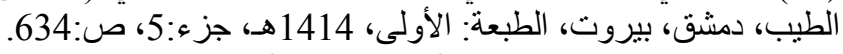

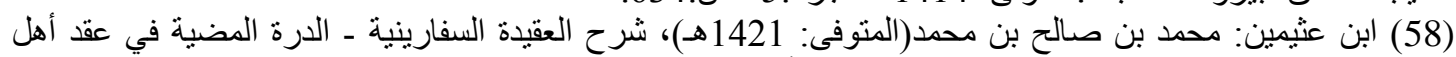

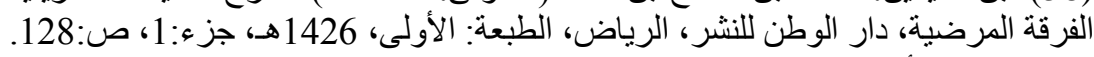
(59) الرازي: أبو عبد الله محمد بن عمر بن الحسن بن الحسين الحسين التيمي(الهنوفى: 606هـ)، التفسير الكبير، دار إحياء التزراث

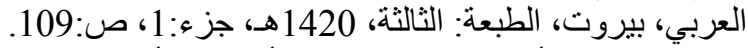

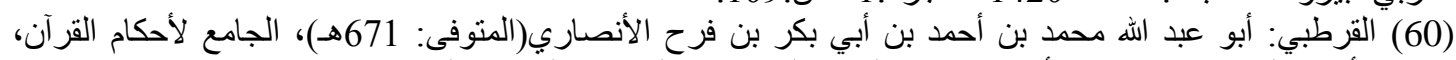

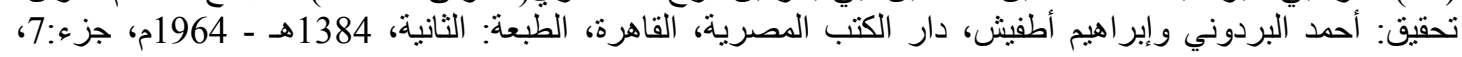

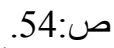
(61) الأخفش الأوسط: أبو الحسن الجاثُعي بالولاء، البلخي ثم البصري(المتوفى: 215هـ)، معانى القرآن للأخفش،

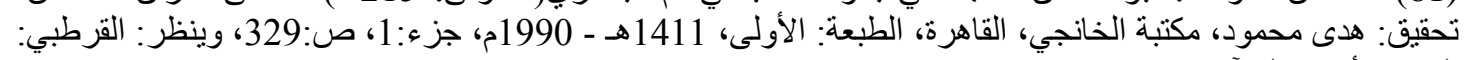

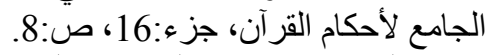

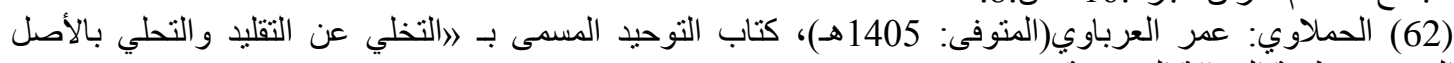

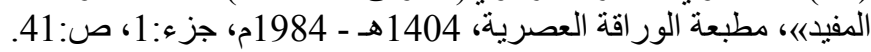




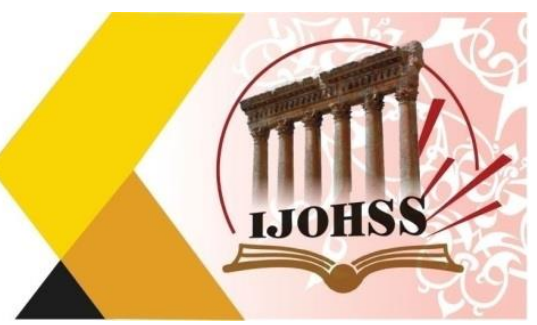

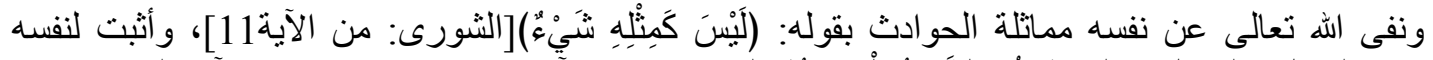

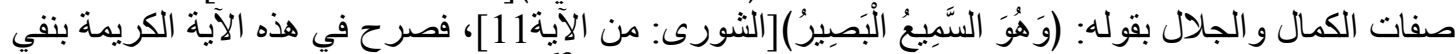

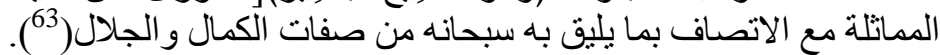

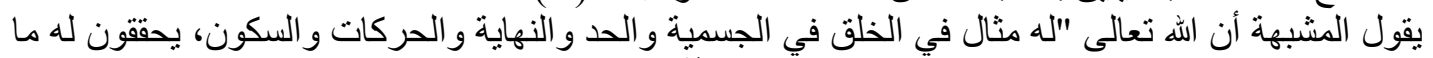

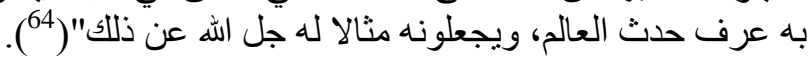

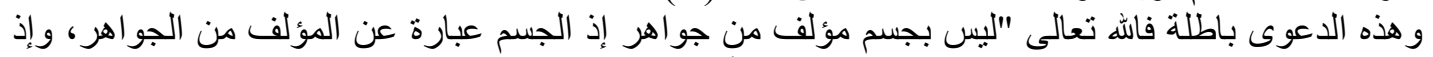

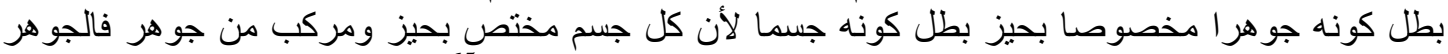

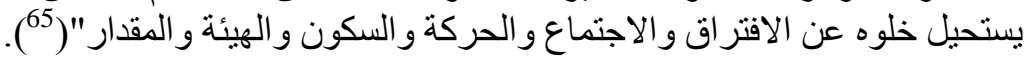

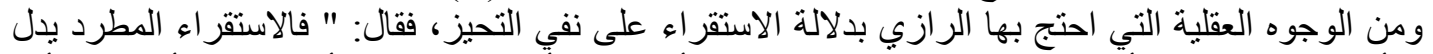

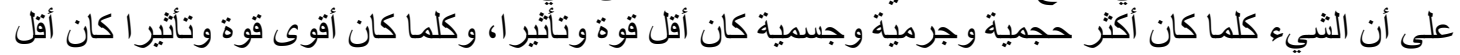

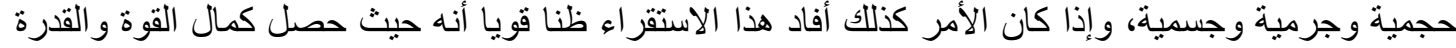

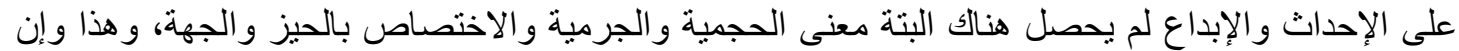

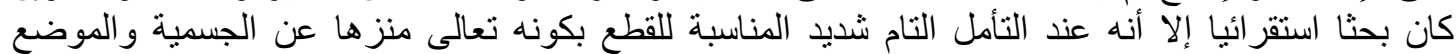

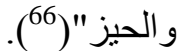
"و اجتمعت الفرقة الناجية أنه سبحانه منزه عن مشابهته لخلقه في ذاته وصفاته، و أنه سبحانه ليس بجسم، خلافاً

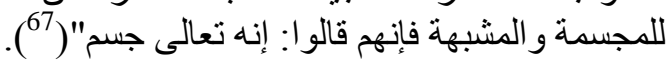

المطلب الرابع: اللأة بعد الموت

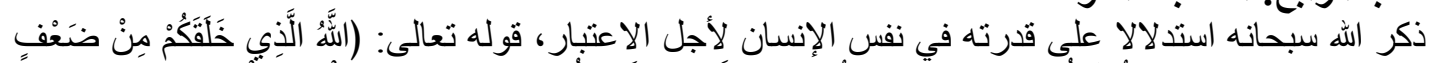

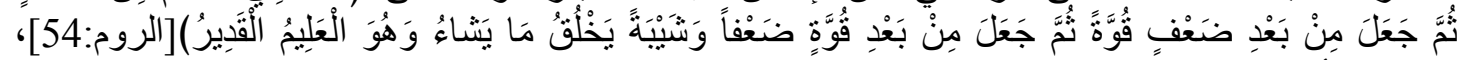

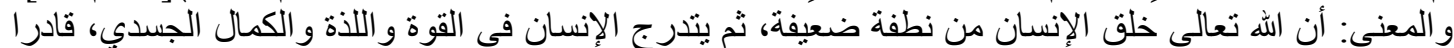

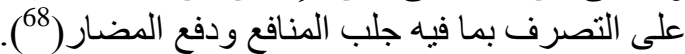

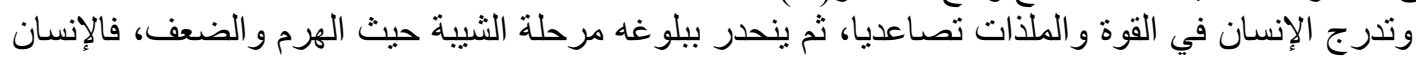

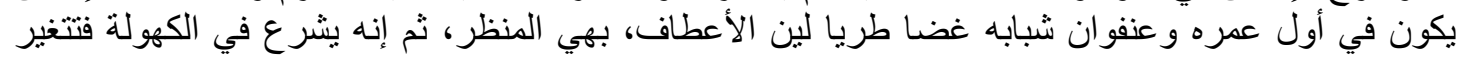

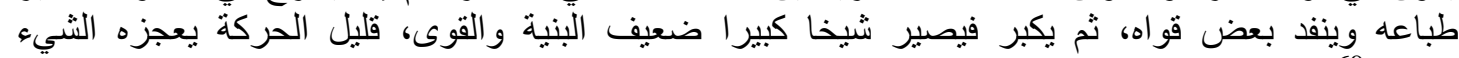

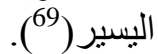

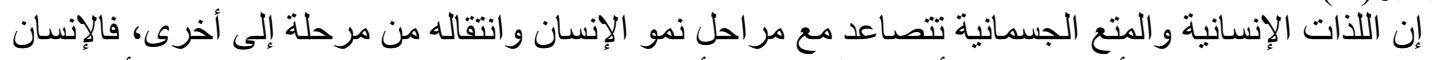

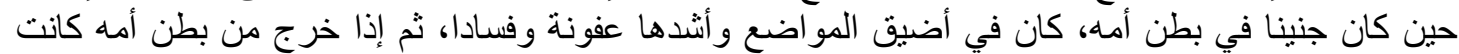

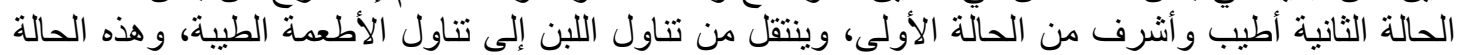

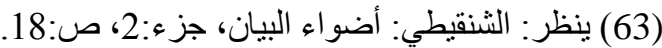

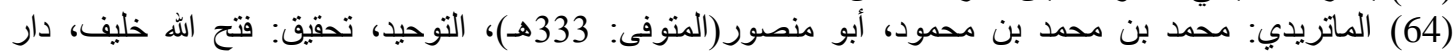

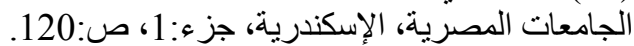
(65) الغز الي: أبو حامد محمد بن محمد الطوسية(المتوفى: 505 هــ) قو اعد العقائد، تحقيق: موسى محمد علي، عالم الكتب،

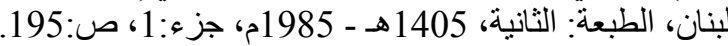

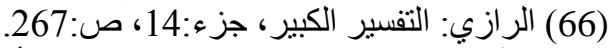

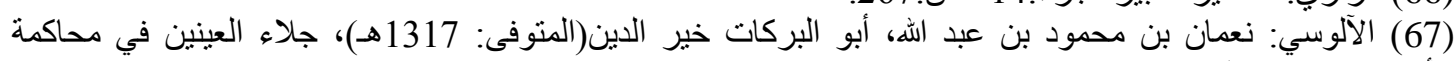

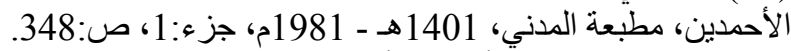

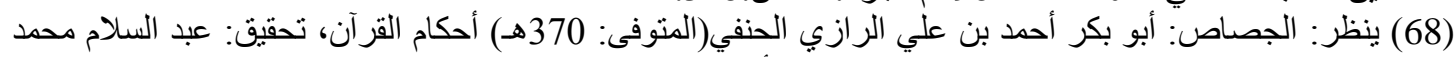

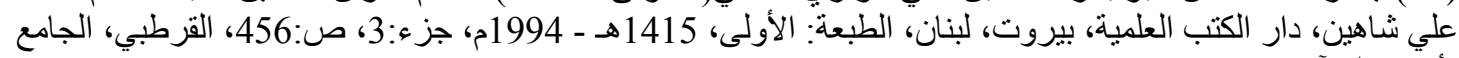

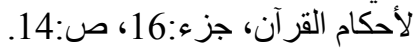
(69) ينظر: ابن كثير : أبو الفذاء إسماعيل بن عمر القرشي البصري ثم الدمشقي (المنوفى: 774هـ)، تفسير القرآن آن العظيه،

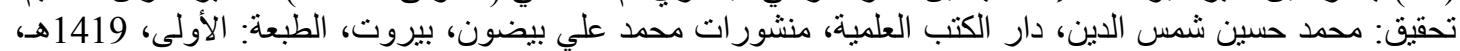




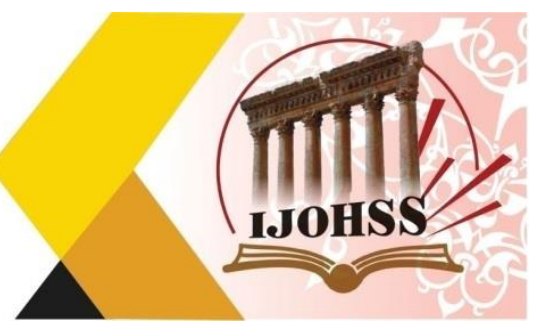

الثالثة لا شك أنها أطيب من الحالة الثانية، ثم إنه بعد حين يصير أمير ا نافذ الحكم على الخلق، أو عالما مشرفا

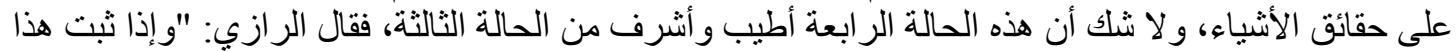

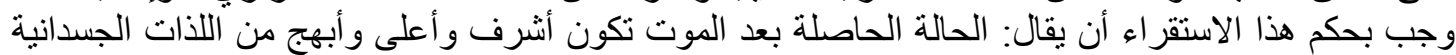

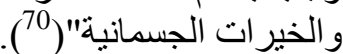

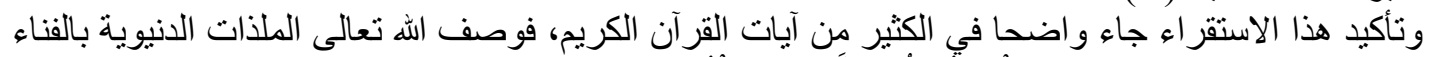

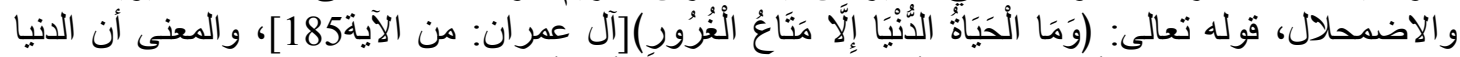

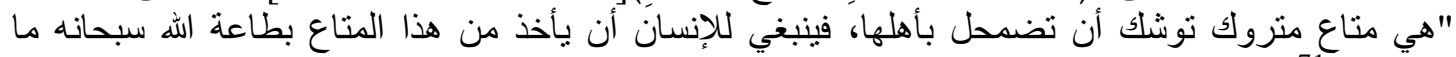

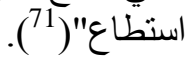

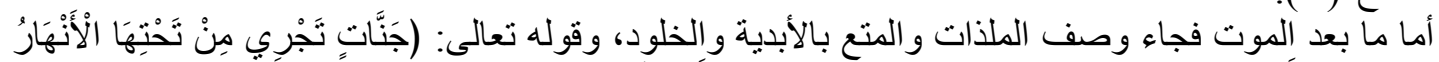

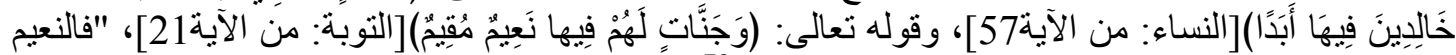

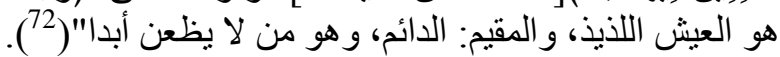

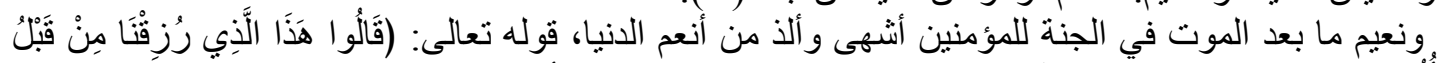

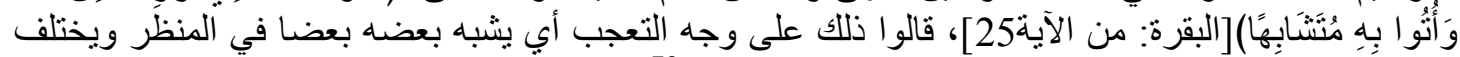

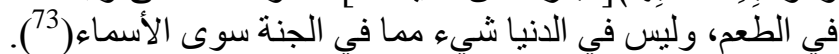

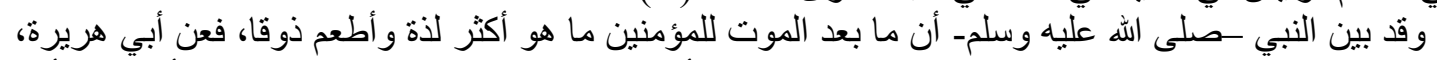

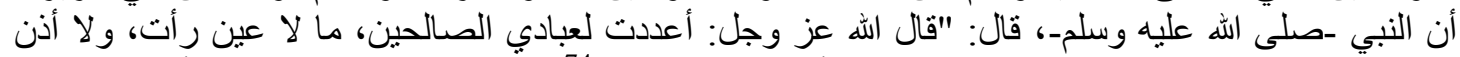

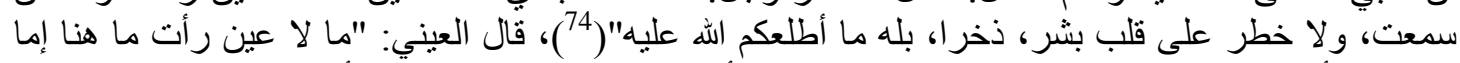

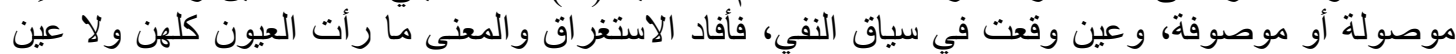

$$
\text { الخخلصة الباحث إلى جملة من النتائج و التوصيات يوجز ها بما بأتي: }
$$

أولا: النتائج: - 2 - الباح:

1- هنالك علاقة وثثقة بين التفسير والاستقر اء، من خلال اعتماد التفسير على قاعدة الاستقر اء، للوصول إلى بيان

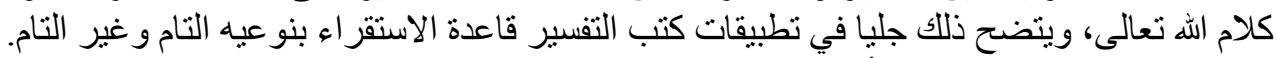

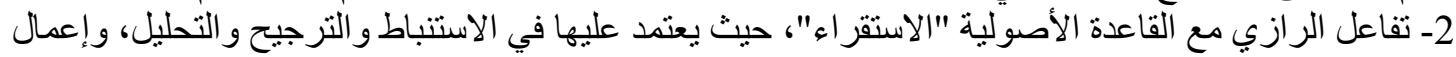

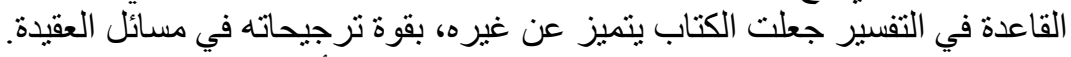

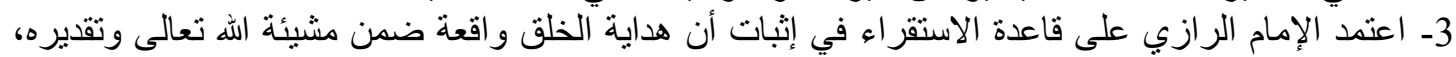

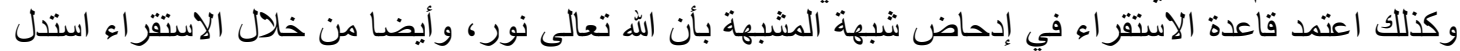

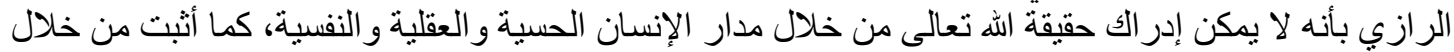

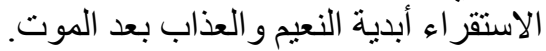

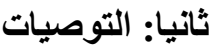

1- يوصي الباحث المهتمين بجانب علوم القرآن و التفسير ، التركيز على قاعدة الاستقر اء، كأداة ذات فاعلية عالية في تفسير القر آن الكريم. 


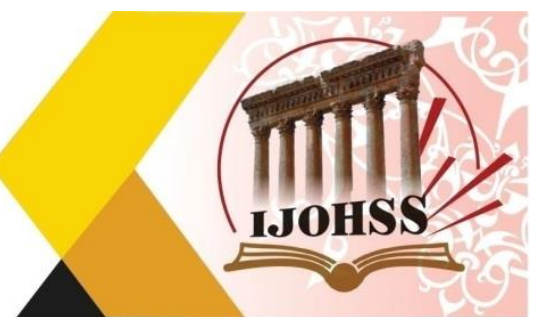

2- يوصي الباحث طلبة الدراسات العليا والباحثين، الكتابة في موضوع الاستقراء وربطه بالتفسير القرآني ، لثنر اء هذا الموضو عالي في مختلف أبو اب العلم الثرعي.

القرآن الكريم 1- ابن الأثثر: علي بن أبي الكرم محمد بن محمد(المنوفى: 630هـ)، الكامل في التاريخ، تحقيق: عمر عبد الكيد

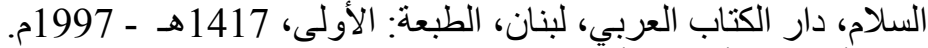

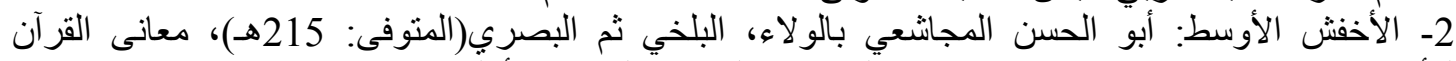

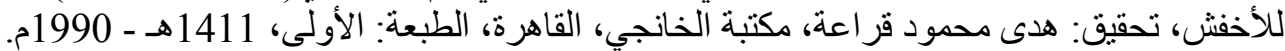

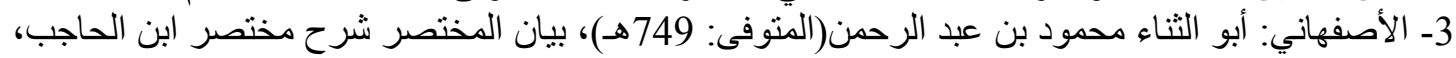

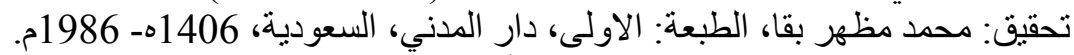

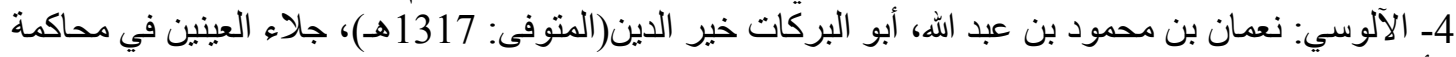

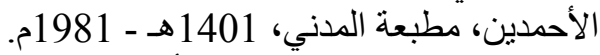

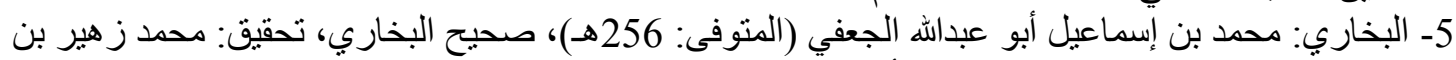

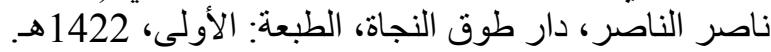

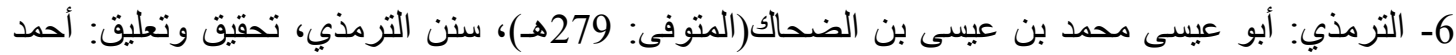

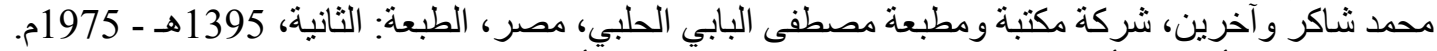

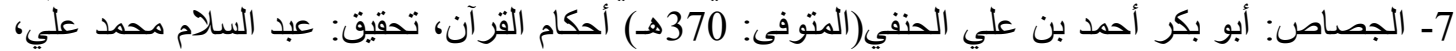

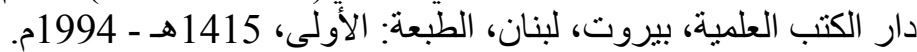

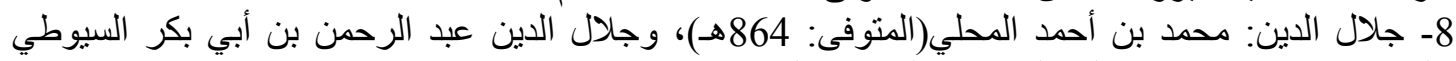

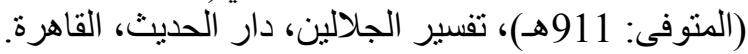

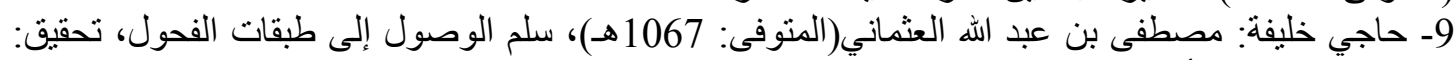

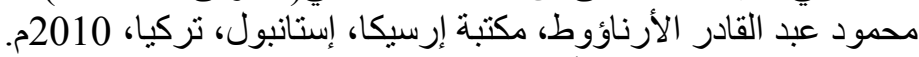

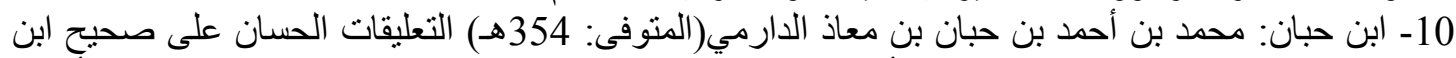

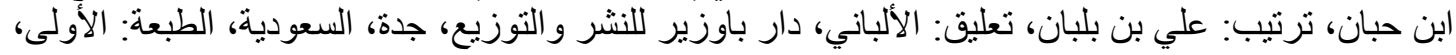

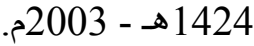
11- ابن حبان: محمد بن أحمد بن معاذ، التميمي البستي(المنوفى: 354هـ)، صحيح ابن حبان، تحقيق: شعيب

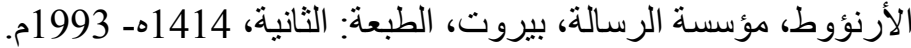

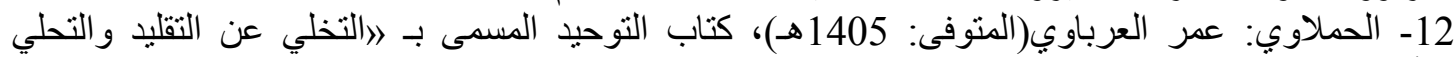

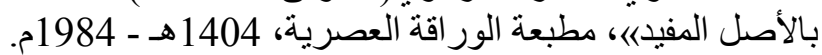

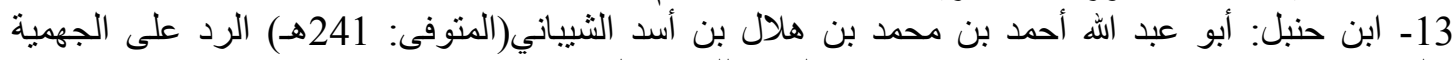

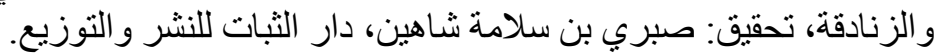

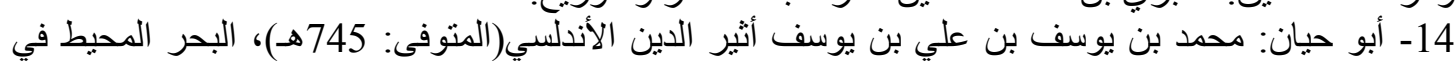

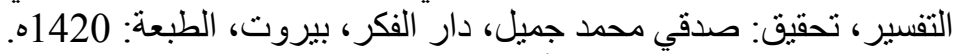

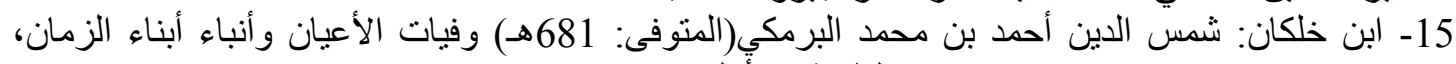

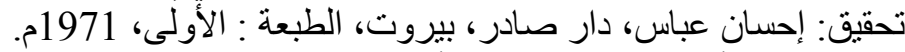

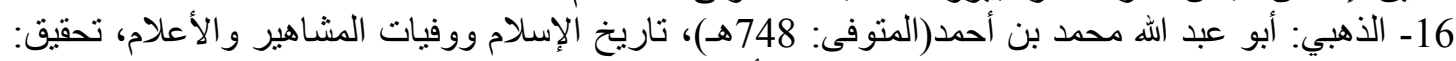

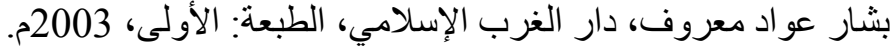
17- الرازي: أبو عبد الله محمد بن عمر بن الحي، الحسن بن الحسين التيمي(المتوفى: 606هـ)، التفسير الكبير، دار

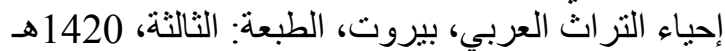

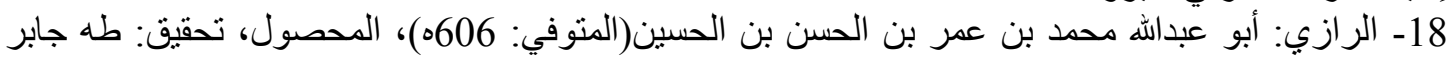

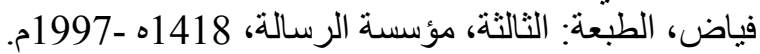




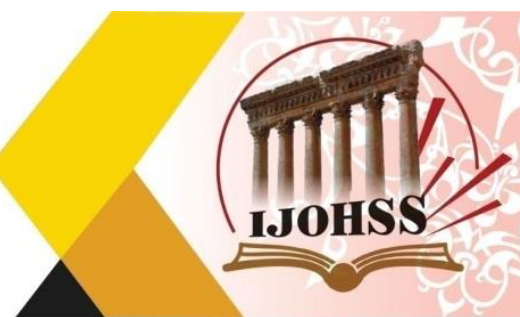

19- الزجاج: إبر اهيم بن السري بن سهل، أبو إسحاق(المتوفى: 311هـ)، تفسير أسماء الله الحسنى، تحقيق: أحمد يوسف الدقاق، دار التقافة العربية. 20- الزركثي: أبو عبد الله بدر الدين الثين محمد بن عبد الله(المتوفى: 794هـ)، البحر المحيط في أصول الفقه،

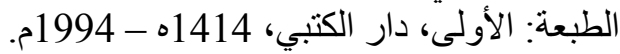
21- الزركلي: خير الدين بن محمود بن محمد الدمشقي(المتوفى: 1396 هـ)، الأعلام، دار العلم للملايين، الطبعة:

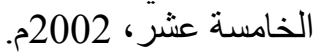
22- السبكي: تاج الدين عبد الوهاب بن بن تقي الدين(المتوفى: 771هـ)، طبقات الثنافعية الكبرى، تحقيق: محمود

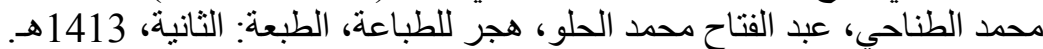

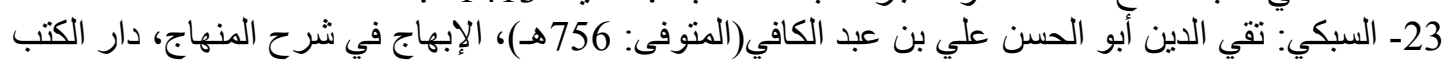

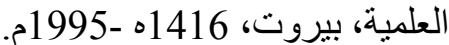

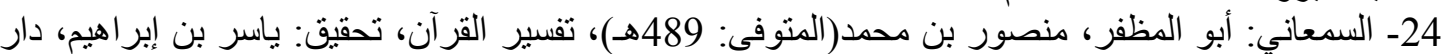

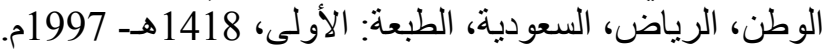
25- السيوطي: عبد الرحمن بن أبي بكر، جلاضلال الطي، الدين(المتوفى: 911هـ)، طبقات المفسرين العشرين، تحقيق:

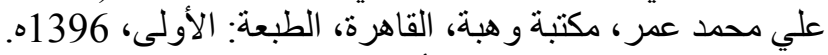

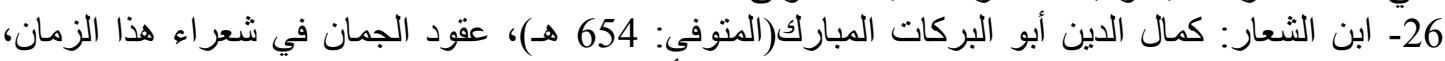

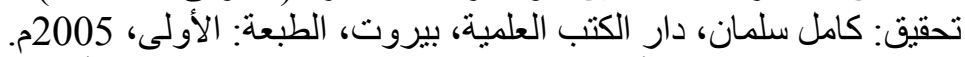

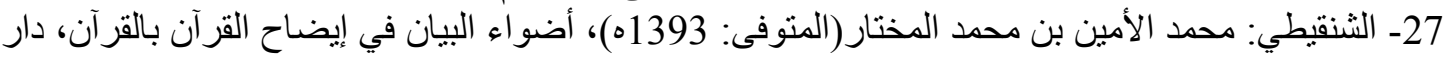

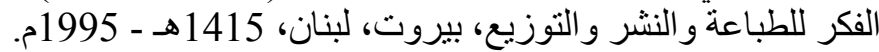

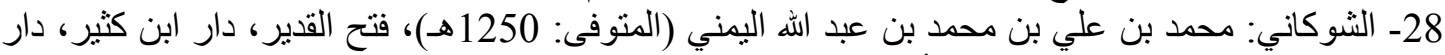

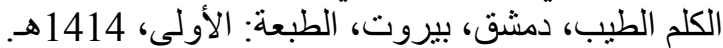
29- الصفدي: صلاح الدين خليل بن أيبك بن عبدئ عبد الله(المتوفى: 764هـ)، الوافي بالوفيات، تحقيق: أحمد

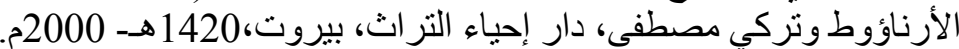

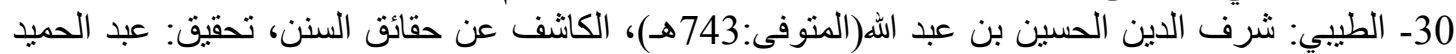

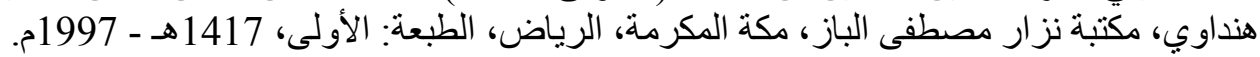

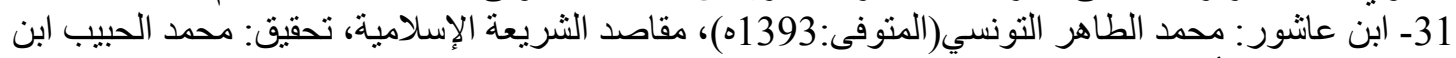

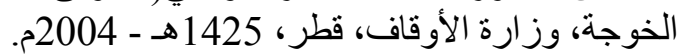

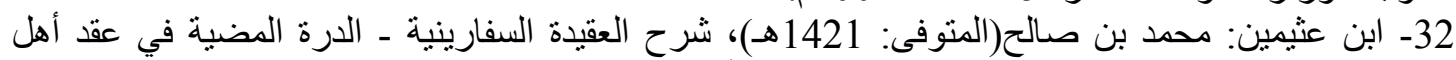

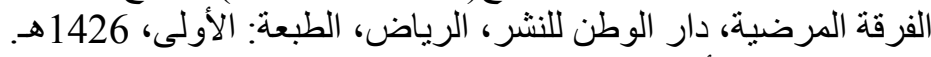

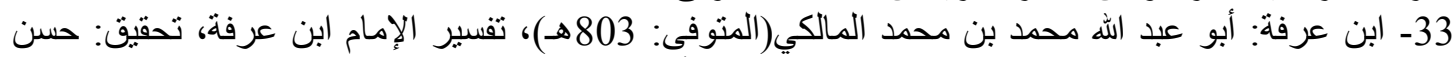

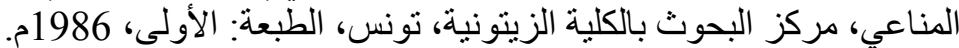

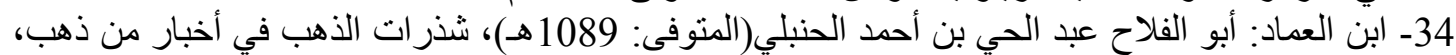

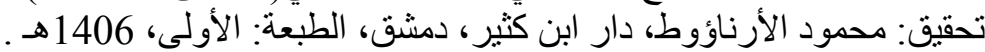

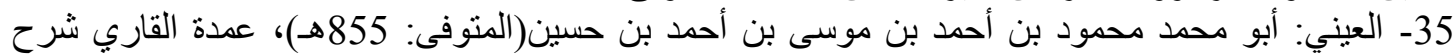

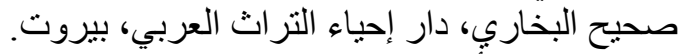

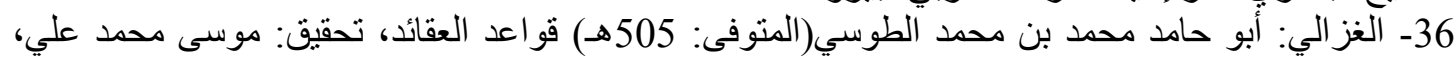

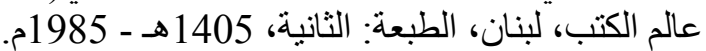
37- الغزالي: أبو حامد محمد بن الطئنة محمد(المتوفي: 505ه)، المستصفى، تحقيق: محمد عبدالسلام عبدالثنافي، الطبعة: الأولَى، دار الكتب العلمية، 1413ه -1993 -1993. 38- الفراهيدي: الخيليل دارئ بن أحمد البصري(المنوفى:170ه)، العين، تحقيق: مهدي المخزومي و إبراهيم

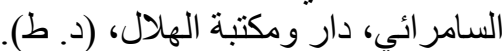

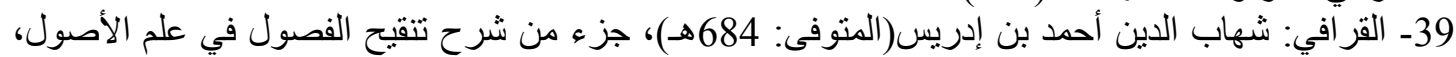

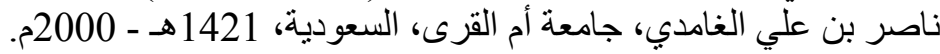




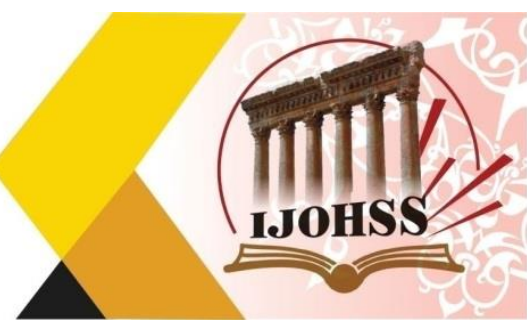

40ـ القر افي: أبو العباس شهاب الدين أحمد بن إدريس(المتوفى: 684هـ)، شرح تنقيح الفصول، تحقيق: طه عبد

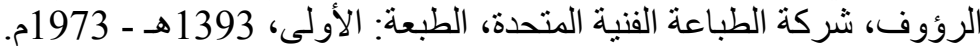
41- القرطبي: أبو عبد الله محمد بن أحمد(المنوفى: 671هـ)، الجامعة الهُعة لأحكام القرآن، تحقيق: أحمد البردوني

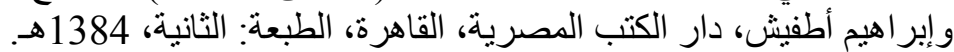

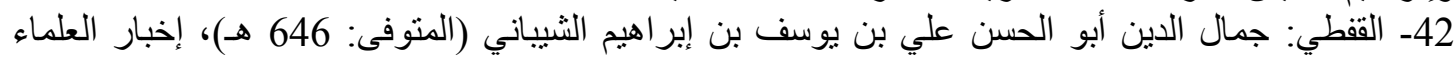

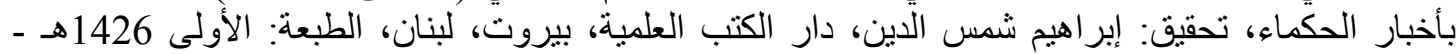
2005م.

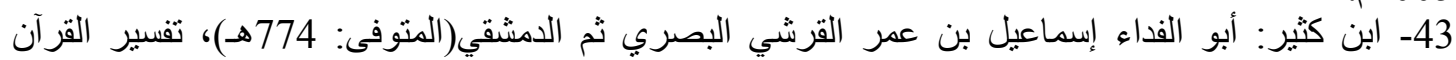

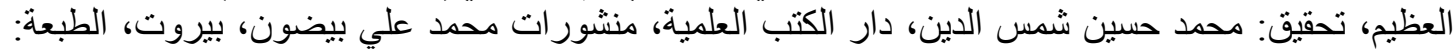

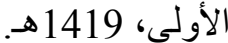
44- ابن كثير: أبو الفداء إسماعيل بن عمر القرشي(المتوفى: 774 هـ) البداية و النهاية، تحقيق: علي شيري، دار

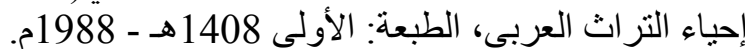

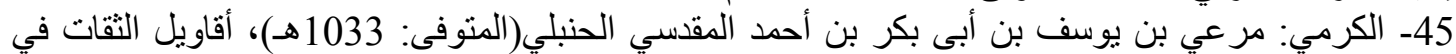

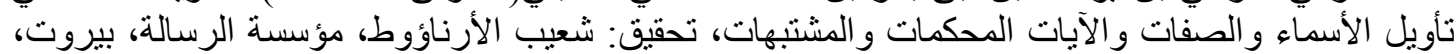

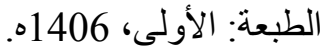
46- الماتريدي: أبو منصور محمد بن محمد(المتوفى: 333هـ)، تأويلات أهل الهئ السنة، تحقيق: مجدي باسلوم، دار

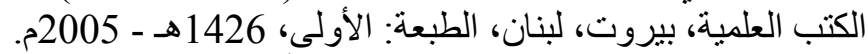

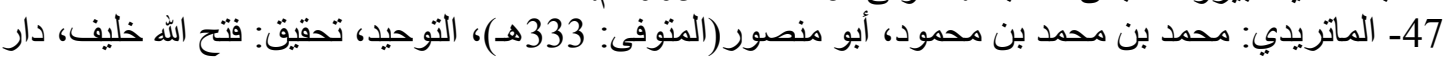
الجامعات المصرية، الإسكندرية.

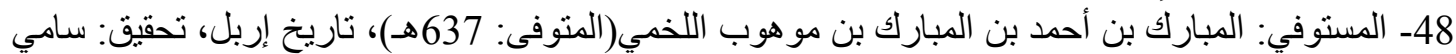

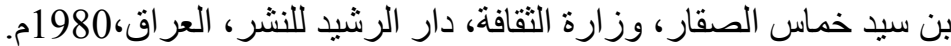

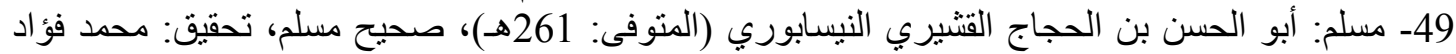
عبد الباقي، دار إحباء التراث العربئ العي، بيروت.

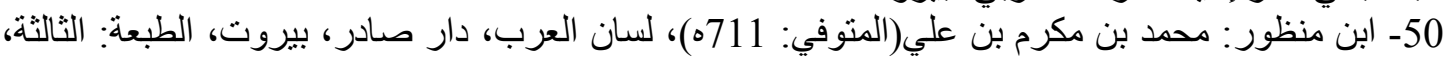
1414 51- ابن الموقت الحنفي: أبو عبد الله شمس الدين محمد بن محمد(المنوفى: 879هـ)، التقرير و التحبير، الطبعة:

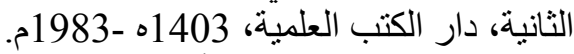
52- ابن النجار: تقي الدين أبو البقاء محمد بن أحمد الحنبلي(المتوفى: 972هـ)، شرح الكوكب المنير، تحقيق:

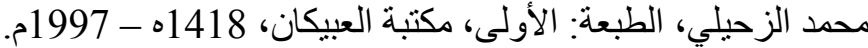

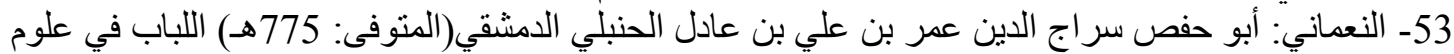
الكتاب، تحقيق: عادل أحمد عبد الموجود وعلي محمد معوض، دارئ دار الكتب العلمية، بيروت، لبنان، الطبعة:

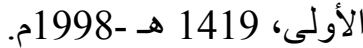
54- النملة: عبد الكريم بن علي بن محمد النملة، الجامع لمسائل أصول الفقه وتطبيقاتها على المذهب الراجح،

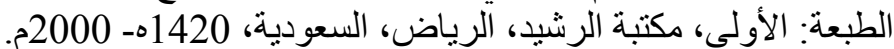

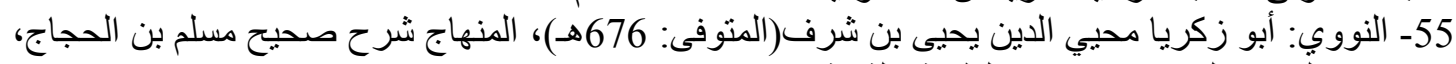

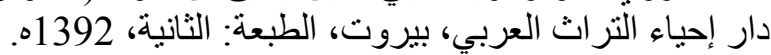

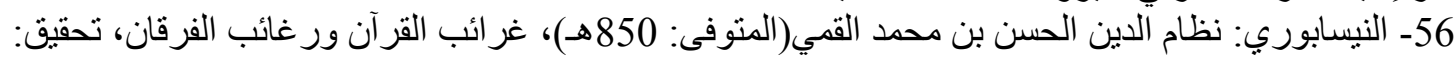

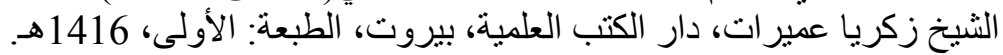

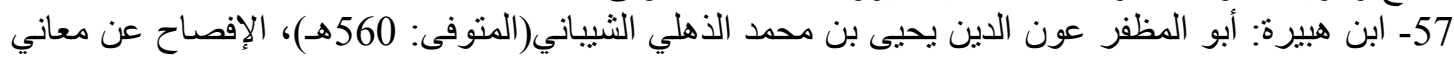

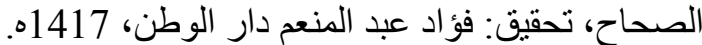

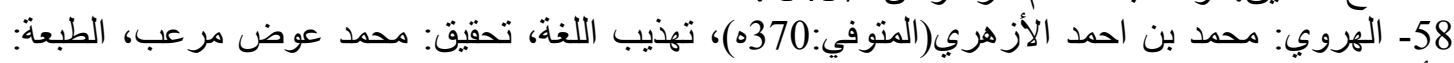
الأولى، دار إحياء التراث العربي، بيروت، 2001م. الازئ 